\title{
Uncertainty Shocks, Adjustment Costs and Firm Beliefs: Evidence From a Representative Survey
}

\section{Working Paper}

Author(s):

Dibiasi, Andreas (1); Mikosch, Heiner (1); Sarferaz, Samad

Publication date:

2021-10

Permanent link:

https://doi.org/10.3929/ethz-b-000512724

Rights / license:

In Copyright - Non-Commercial Use Permitted

Originally published in:

KOF Working Papers 496 


\section{EHzürich}

\section{KOF Swiss Economic Institute}

Uncertainty Shocks, Adjustment Costs and Firm Beliefs: Evidence From a Representative Survey

Andreas Dibiasi, Heiner Mikosch, and Samad Sarferaz 


\section{KOF}

ETH Zurich

KOF Swiss Economic Institute

LEE G 116

Leonhardstrasse 21

8092 Zurich, Switzerland

Phone +41 446324239

Fax +41446321218

www.kof.ethz.ch

kof@kof.ethz.ch 


\title{
Uncertainty Shocks, Adjustment Costs and Firm
}

\section{Beliefs: Evidence From a Representative Survey*}

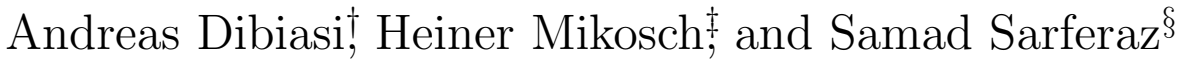

October 25, 2021

\begin{abstract}
This paper studies the dynamic effects of an uncertainty shock on firm expectations. We conduct a survey that confronts managers from a representative firm sample with a model-consistent uncertainty shock scenario. An exogenous increase in uncertainty significantly reduces managers' expected investment, employment and production in the short and mid run. We collect novel direct firm-level measures for different types of capital and labor adjustment costs. Adjustment costs vary strongly across sectors and types. They help explain firms' reactions to the shock, which provides evidence for the relevance of real-options channels. We compare the findings to DSGE and VAR results.
\end{abstract}

JEL classifications: C83, D83, D84, E22, E23, E24

Keywords: Uncertainty, Shock, Firms, Survey, Vignette, Expectations, Investment, Employment, Production

*The authors thank Klaus Abberger, Andreas Fuster, Michael Weber, Johannes Wohlfart, and participants at the 10th ifo Conference on Macroeconomics and Survey Data for helpful comments. The authors further thank Sebastian Heinrich for valuable research assistance. Financial support from the French National Agency for Research (ANR) via the grant ANR-20-CE26-0013 is gratefully acknowledged.

†Aix-Marseille University, AMSE, Marseille, France, andreas.dibiasi@univ-amu.fr.

${ }^{\ddagger}$ KOF Swiss Economic Institute, ETH Zurich, Switzerland, mikosch@kof.ethz.ch.

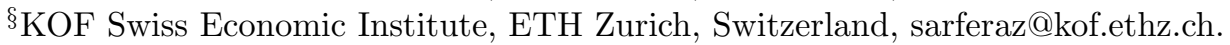




\section{Introduction}

The theoretical channels connecting uncertainty and the economy are subject to a vivid debate. Real options stand out as an important mechanism explaining the negative macroeconomic effects of uncertainty. ${ }^{1}$ According to the real-options channel, which goes back to at least Bernanke (1983), a surge in uncertainty causes firms to wait and postpone their business decisions. This leads to an decrease in investment and hiring (e.g., Bloom, 2009, Bloom et al., 2018, and Fernández-Villaverde and Guerrón-Quintana, 2020 for recent theoretical models using real frictions). While from a theoretical point of view real options cause firms to pause their investment and employment decisions in the light of an uncertainty shock, it is difficult to estimate real-options effects empirically as it is difficult to identify uncertainty and observe adjustment costs at the firm level.

In this paper, we study firms' beliefs about their production, employment and investment reactions to an exogenous change in uncertainty. For this, we conduct a survey among the CEOs and CFOs of a representative firm sample of the Swiss economy. During the survey, the managers are confronted with a vignette, i.e. a hypothetical scenario, that entails an uncertainty shock as in a theoretical model. The survey consists of three steps. First, we collect the distribution of firms' long-term turnover expectations as well as detailed production, investment and employment plans over the next four half years. In a second step, we ask them about a battery of additional characteristics including firing and hiring costs and the degree of capital irreversibility. Later on, these firm-level characteristics will allow us to study the role of real-options channels in the beliefs of managers. In a third step, we confront the firm managers with a vignette according to which the government announces to hold a referendum on a far-reaching law change. The vignette is designed such that, as a consequence of the announcement, each manager's previously recorded uncertainty on long-term turnover increases until the referendum vote and her

\footnotetext{
${ }^{1}$ See Bloom (2014) and Fernández-Villaverde and Guerrón-Quintana (2020) for a discussion of further channels.
} 
mean expectation on long-term turnover stays unchanged. Finally, the managers are asked to update their previously stated production, investment and employment plans for the next four half years. The managers' beliefs about the effect of the uncertainty shock result from taking the difference between the baseline plans and the updated plans. When empirically studying the effects of uncertainty shocks, it is usually not easy to separate uncertainty shocks (second moment shocks) from mean expectation shocks (first moment shocks), since both usually coincide in reality. Bloom (2014) considers this as one of the major challenges for the research on the economic effects of uncertainty. To the best of our knowledge, we are the first to tackle this identification challenge by means of a vignette survey experiment. The hypothetical vignette allows us to disentangle first from second moment effects by imposing an exogenous shift in the managers' uncertainty of their expectations, while holding their mean expectations constant. Concretely, we inform each manager that a referendum will be held whose adoption will increase her firm's expected long-term demand and whose rejection will decrease the expected demand. We further inform the managers that, according to the current polls, there is a 50-50 chance of adopting or rejecting the referendum. Based on firms' previously reported baseline demand expectations, we compute the increase and decrease in demand expectations individually for each firm. We thereby create a doubling of demand uncertainty, while keeping the mean of the demand expectations unchanged.

We find that the increase in uncertainty significantly reduces expected production, investment and employment over the subsequent four half years, according to the beliefs of the firm managers. Investment is expected to decrease more than production and production is expected to decline more than employment. Using standard aggregation procedures we build value added weighted average effects over the representative firm sample. After two years, the average level of investment is $6.3 \%$ below its level in the no shock scenario. The average levels of employment and production are $1.6 \%$ and $1.9 \%$ below their respective baseline levels. The time profile of the managers' predicted investment, employment and 
production effects in response to the uncertainty shock fits surprisingly well the profile of impulse responses obtained from a VAR model (as, for instance, in Jurado, Ludvigson and Ng, 2015 as well as Basu and Bundick, 2017). Similar to Bachmann, Elstner and Sims (2013), Jurado, Ludvigson and Ng (2015), and Basu and Bundick (2017) but in contrast to the results of Bloom (2009) and Caggiano, Castelnuovo and Nodari (2020), we do not find evidence that real activity overshoots after its initial decline, at least not within the first two years.

Several authors have empirically investigated the relevance of real options for the effect of uncertainty on firms and the economy (e.g., Guiso and Parigi, 1999, Julio and Yook, 2012, Bloom, Bond and Van Reenen, 2007, Gulen and Ion, 2015, Jens, 2017, Dibiasi et al., 2018, and Bloom et al., 2019). We contribute to this literature by regressing firms' expected investment, employment and production responses to the uncertainty shock scenario on their firm-level adjustment costs measures. To the best of our knowledge, this is the first empirical firm-level study that jointly examines the role of capital and labor adjustment cost channels in the transmission of uncertainty shocks. The regression analysis yields that both capital and labor irreversibility are important transmission channels of firms' investments responses to an uncertainty shock. A one standard deviation decrease in the firm-specific investment resale value amplifies the expected fall in investment in response to the shock by 2.6 percentage points. Further, a one standard deviation increase in labor adjustment costs increases the investment drop by 2.1 percentage points. Also, lower capital reversibility intensifies the expected drop in real output and lower labor reversibility amplifies the employment drop. We split the labor adjustment costs into hiring and firing costs and find that the latter tends to matter more than the former. Moreover, we find that firms' degree of labor attrition affects the relevance of the labor irreversibility channel. Specifically, a high labor attrition rate mutes the negative effect of labor adjustment costs on the investment, employment and real output responses to the uncertainty shock. The suggested reason is that higher labor adjustment costs limit 
firms' adjustment ability less if the firm-specific labor attrition is high anyway.

Our paper further connects to the literature on real capital and labor adjustment costs. Taking into consideration the importance of real adjustment costs in theoretical models, the existing literature offers surprisingly little evidence on their actual values. In this paper, we provide direct measures of firing costs, hiring costs, labor attrition, and capital irreversibilty at the firm-level. While few studies provide measures on firing and hiring costs, to the best of our knowledge, we are the first to directly survey capital resale values. These direct measures help to improve our understanding of capital irreversibility. Currently, the literature offers a broad range of indirect estimates for capital resale values. For instance, Ramey and Shapiro (2001) place the capital resale value somewhere between $20 \%$ and $60 \%$ of the initial costs. Cooper and Haltiwanger (2006) find a resale value of $97.5 \%$ and Bloom (2009) estimates it to be $66.1 \%$. This wide range of estimates makes it difficult to calibrate the resale value in theoretical models. Gilchrist, Sim and Zakrajšek (2014) calibrate the resale value in their model to 50\%. Khan and Thomas (2013) and Lanteri (2018) calibrate it to be equal to $95.4 \%$ and $93.3 \%$ respectively. Our collected data suggests a mean aggregate capital resale value of $52.8 \%$. However, our firm-level data shows that resale values differ strongly with sector, firm size and type of investment. This strong heterogeneity of resale values uncovered by our data offers a possible explanation for the broad range of estimates in the literature. Depending on what kind of investment or what kind of sector one includes in the analysis, one might find a different resale value estimate. Moreover, the strong firm-level heterogeneity of capital resale values - and to a lesser extent of firing and hiring costs - suggests a more careful consideration of heterogeneity of adjustment costs in heterogeneous firm models.

Our study is part of a dynamically growing strand of research in macroeconomics that embeds experimental settings into household or firm surveys in order to study the expectation formation and decision making of economic agents (e.g., Jappelli and Pistaferri, 
2014, Drechsel et al., 2015, Armantier et al., 2016, Cavallo, Cruces and Perez-Truglia, 2017, Armona, Fuster and Zafar, 2018, Binder and Rodrigue, 2018, Coibion, Gorodnichenko and Kumar, 2018, Andre et al., 2019, Christelis et al., 2019, Fuster et al., 2020, Coibion, Gorodnichenko and Weber, 2019, Coibion et al., 2019, Drechsel et al., 2019, Coibion, Gorodnichenko and Ropele, 2020, Jappelli and Pistaferri, 2020, Roth and Wohlfart, 2020, Christelis et al., 2021, Coibion et al., 2021b, Coibion et al., 2021a, Fuster, Kaplan and Zafar, 2021, Link et al., 2021, and Mikosch et al., 2021). Method wise our paper relates to Andre et al. (2019). In a US household survey and a worldwide expert survey, they present respondents macroeconomic shock scenarios (oil supply, monetary policy, government spending, income tax) and measure their beliefs on how unemployment and inflation responds to the shock. Like Andre et al. (2019) we confront respondents with a macroeconomic shock scenarios using the the method of hypothetical vignettes. However, we limit ourselves to a macroeconomic uncertainty shock scenario and study the believed effects on investment and production. Topic wise our paper relates to the uncertainty study of Coibion et al. (2021a). The authors embed randomized control trials into a euro area household survey and treat respondents with information on the first and/or second moments of professional forecasts of economic growth, thereby generating exogenous changes in households' perceived macroeconomic uncertainty. It turns out that higher uncertainty induces households to reduce their spending on goods and services as well as their propensity to invest in mutual funds. Our paper adds to the insights of Coibion et al. (2021a) by studying the effects of exogenous changes in uncertainty on firms. Both Coibion et al. (2021a) and we find that macroeconomic uncertainty can have large negative effects on economic outcomes. ${ }^{2}$

We extend the vignette method along two dimensions. First, uncertainty and other macroeconomic shocks concern economic agents very differently. This is a challenge if

\footnotetext{
${ }^{2}$ Mikosch et al. (2021) find that, as predicted by models of endogenous information acquisition, an exogenous increase in perceived exchange rate uncertainty increases firms' demand for information about exchange rate developments.
} 
the researcher wants to compare the responsiveness to a macroeconomic shock across individual units: it is a priori not clear whether an agent is responding strongly (weakly) to a shock, just because she has been hit hard (weakly) by it or because she is very responsive (resilient) to it. To address this issue, we initially collect firms' baseline uncertainty on future turnover. The vignette then uses this information and shifts each individual uncertainty by the same relative amount (doubling of the standard deviation of each manager's firm-specific revenue expectation distribution). Hence, the vignette is designed such that

the macroeconomic uncertainty scenario exogenously shifts the turnover uncertainty by the same amount for all firms. Second, we let the firm managers assess the effects of the uncertainty shock over four subsequent half years. This allows us to learn how persistent the effects of the shock are according to the beliefs of the managers and whether the time profile coincides with impulse responses from a general equilibrium model, a partial equilibrium model and a VAR.

The remainder of the paper is structured as follows. In Section 2, we discuss theoretical channels connecting uncertainty and the real economy. Section 3 describes the survey and the uncertainty vignette. Section 4 then presents our results and Section 5 concludes.

\section{Uncertainty Shocks and Adjustment Costs}

In this section we shortly revisit the theoretical channels that connect uncertainty and the real economy. Thereby, we focus on the real-options channels and the associated role of labor and capital adjustment costs for the impact of uncertainty on the economy. In order to dissect the various real-options channels through which uncertainty might affect the economy within a theoretical framework, we need a model that considers an economy with uncertainty shocks and includes capital and labor adjustment costs. The dynamic stochastic general equilibrium model proposed by Bloom et al. (2018) includes these features. The real business cycle model considers an economy with a representative 
households that aims to maximize its life-time discounted utility. The household chooses how much it wants to consume, work and invest in order to maximize its life-time utilities. On the firm side, the model features an economy with heterogeneous firms that use labor and capital to produce a final good with the objective to maximize the lifetime discounted value of their firm. Firms are endowed with a Cobb-Douglas production function that is subject to an exogenous process of productivity that has a firm-level and a macroeconomic component. Both the macroeconomic and the firm-level productivity process varies in the first and second moment, with changes in second moment representing changes in uncertainty. Thus, in this model, uncertainty shocks represent an increase in the variance of the distribution from which future realisations of productivity are being drawn. In the model, firms react to changes in productivity by adjusting capital and labor. However, adjusting capital and labor comes at a cost that firms have to take into account when maximizing their firm value.

We chose the model by Bloom et al. (2018) because of the exhaustive way to model capital and labor adjustment costs. The model includes two types of labor adjustment $\operatorname{costs}\left(A C^{n}\right)$. Firms face fixed and linear costs when adjusting labor. Fixed costs $\left(C_{L}^{F}\right)$ represent a lump sum cost that arises when employees are hired or fired. This cost does not depend on the size of the adjustment but on business conditions. One can think of these costs as arising from the deficiency in production owing to an experienced employee leaving the company or a new employee entering it. In contrast to fixed costs, linear costs depend on the size of the labor adjustment, but are independent from the state of the economy. These costs represent hiring $\left(C_{L}^{H}\right)$ and firing costs $\left(C_{L}^{F}\right)$ and include, among others, recruiting and training costs for new employees and severance payment when laying off employees. Equation (2) formally introduces labor adjustment costs:

$$
A C^{n}=\mathbb{1}(|s|>0) y(z, A, k, n) C_{L}^{F}+\mathbb{1}(s>0) C_{L}^{H} w+\mathbb{1}(s<0) C_{L}^{F} w
$$


where the term $\mathbb{1}(\cdot)$ represents an indicator function and $s$ represents the labor adjustment. Further, the function $y(z, A, k, n)$ represents the production function with $z$ and $A$ indicating the firm-level and aggregate productivity. $k$ indicates the amount of capital and $n$ states the labor input. $w$ represents the annual wage. The model also considers two types of capital adjustment costs $\left(A C^{k}\right)$. Firms face fixed investment $\operatorname{costs}\left(C_{K}^{F}\right)$ that occur each time a firm adjusts its capital stock as well as additional costs in form of a resale loss when firms sell off parts of their capital stock. Fixed costs depend on the level of production and thus on business conditions. Fixed capital adjustment costs represent the cost that arises because of disruption or slow down in production owing to the installation of the new capital. The resale loss represents the partial irreversibility of capital $\left(1-C_{K}^{R V}\right)$ and represents a cost that is expressed in terms of a fraction of the capital that is being sold. Hereby, $C_{K}^{R V}$ represents the capital resale value. Equation (2) formally introduces capital adjustment costs:

$$
A C^{k}=\mathbb{1}(|i|>0) y(z, A, k, n) C_{K}^{F}+\mathbb{1}(i<0)\left(1-C_{K}^{R V}\right)|i|,
$$

where $i$ represents investment.

In order to examine the importance of the different adjustment costs in shaping the response of an economy to an uncertainty shock, we calibrate, solve and simulate the model of Bloom et al. (2018) three times. First, we consider all channels as in the original paper. In a second step, we turn off the real-options investment channel. That is, we set the resale loss to zero. Fixed capital adjustment costs are already set to zero in the original paper. In a final version, we consider the real-options investment channel, but set labor adjustment costs to zero. In order to ensure comparability with Bloom et al. (2018) and the RBC literature in general, we do not change the calibration proposed by Bloom et al. (2018), except for the adjustment cost parameters. Table 1 summarizes our parameter choices. 
Table 1: Model Calibration

\begin{tabular}{llccc}
\hline \hline Parameter & Description & $\begin{array}{c}\text { All } \\
\text { Channels }\end{array}$ & $\begin{array}{c}\text { No } \\
\text { CAdj Costs }\end{array}$ & $\begin{array}{c}\text { No } \\
\text { LAdj Costs }\end{array}$ \\
\hline$C_{L}^{F}$ & Fixed hiring/firing costs (\% of annual sales) & 0.021 & 0.021 & 0.0 \\
$C_{L}^{H}$ & Per capita hiring (\% of annual wage bill) & 0.018 & 0.018 & 0.0 \\
$C_{L}^{F}$ & Per capita firing cost (\% of annual wage bill) & 0.018 & 0.036 & 0.0 \\
$C_{K}^{F}$ & Fixed capital adjustment costs (\% of annual sales) & 0.0 & 0.0 & 0.0 \\
$C_{K}^{R V}$ & Resale value (\% of initial investment) & 0.661 & 0.0 & 0.661 \\
\hline \hline
\end{tabular}

Notes: This table presents the model calibration and parameter choices. The calibration reflects a quarterly calibration of the model and is based on Bloom et al. (2018).

We use the three calibrated models to simulate the theoretical reaction of the economy to an uncertainty shock. In the model, an uncertainty shock represents an increase in the variance of the shock distribution from which future realisations of productivity will be drawn. This corresponds roughly to the uncertainty shock that we incorporate in the hypothetical vignette. Figure 1 presents the impulse responses of output, investment and employment to an uncertainty shock for the three different calibrations. The black lines presents the impulse response to an uncertainty shock considering a model with capital and labor adjustment costs. This specification corresponds to the calibration of Bloom et al. (2018). The brown line shows the effects of an uncertainty shock on an economy with no capital adjustment costs. Finally, the blue line depicts the impulse response of the same uncertainty shock in an economy with no labor adjustment costs.

The brown line in Figure 1 illustrates that when no capital adjustment costs are present in an economy, an increase in uncertainty about future productivity causes a drop and overshoot of output, investment and employment. The reason for this result is related to the Oi (1961), Hartman (1972), and Abel (1983) effect. The Oi-Hartman-Abel effect provides the insight that an increase in the variance of productivity increases investment because the optimal capital and labor choices are convex in productivity. In case one reduces all labor adjustment costs, i.e. fixed labor adjustment costs, hiring and firing costs, to zero, the negative effects of uncertainty on output, investment and employment 

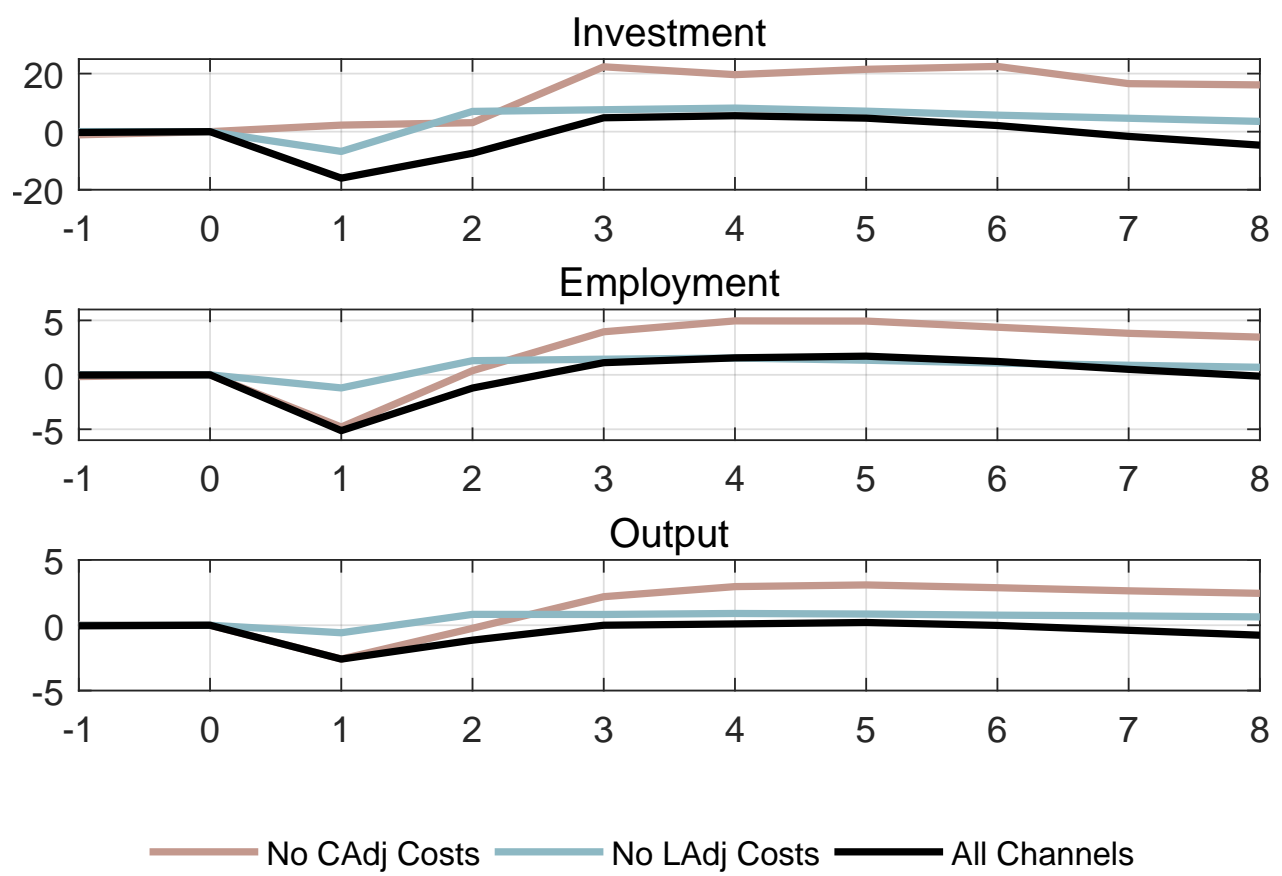

Notes: This figure presents the role of adjustment costs for the propagation of uncertainty shocks within the general equilibrium model by Bloom et al. (2018). The impulses responses present the percentage deviation of investment, employment, and output from the steady state for the first 8 quarters after the shock. The black lines depict the impulse response of investment, employment, and output to an uncertainty shock under the original calibration. The blue lines show the impulse responses when labor adjustment costs are set to zero. The brown lines depict the impulse responses in the absence of capital adjustment costs.

decrease. This analysis reveals the significance of adjustment costs parameter in theoretical models. Given this important role of adjustment costs for the real-options effects of uncertainty, we believe that it central to have precise information about these key characteristics in order to empirically identify the real-options channels. Thus, when designing our survey, we tried to levy these relevant characteristics as closely to our theoretical understanding as possible.

\section{The Survey}

The core objective of this paper is to understand firms' beliefs about the consequences of uncertainty. To address this question, we conducted a survey among the CEOs and 
CFOs of a representative firm sample of the Swiss economy. In this survey, we confronted the managers with an uncertainty shock scenario and asked them to update their firms' production, employment and investment plans in response to the vignette information.

\subsection{Representative Firm Sample}

We added the survey to the spring 2017 wave of the KOF Investment Survey. This bi-annual survey was established in 1967 and collects realized and projected investment figures and other information from Swiss firms. The firm panel of the KOF Investment Survey has been sampled from the population of around 60000 registered Swiss firms (as taken from the Business Register of the Swiss Federal Statistical Office) and included 3351 Swiss firms at the time of the survey. The usual procedures for prevention of sampling errors were applied (e.g., Cochrane, 1977). Stratified random sampling following, e.g., Dalenius and Gurney (1951) ensured that the firm panel is a representative sample of the Swiss economy for each size class on the industry level (NACE-2-digit size class level).

The participating firms received invitation letters by mail and by e-mail and were invited to participate in the survey via the usual purpose-designed web interface used for the KOF Investment Survey. The questionnaire was available in German, French, Italian and English according to respondents' language preference. We designed the questionnaire in a way to minimize survey fatigue and dropouts. We first met with other economists to ensure the economic integrity of our questionnaire. We then consulted survey experts to improve our survey design. Next, we met with accountants and asked them to translate our economic language into a language that is actually understood by firms. Finally, in October 2016, we personally met and discussed our questionnaire with 5 firm managers. This pre-test helped us to further improve the questionnaire language-wise and remove remaining ambiguity from our questions. Appendix E provides the English version of the questionnaire. 1409 firms participated in the survey. The response rate was 42\%, a normal value compared to other waves of the KOF Investment Survey. Most of the 
respondents are the CEOs or CFOs of the firms (e.g., Abberger, Bannert and Dibiasi, 2014, for a general assessment of respondents' characteristics in KOF business tendency surveys). The median answering time for the additional questionnaire was 14.6 minutes.

\subsection{Structure of the Survey}

The questionnaire is divided into three parts. The first part collected firms' revenue and cost structure and their revenue expectations. Specifically, we asked the CEOs and CFOs to provide the mean, the 1\%-percentile and the $99 \%$-percentile of their expectation distribution on their respective firm's annual revenue for the next year (i.e. the year 2018).

For later purpose, denote these values by $E_{i, t-1}\left[A_{i, t}\right], \underline{Q}_{i, t}$ and $\bar{Q}_{i, t}$. The information will later in the survey allow us to specify a macroeconomic uncertainty shock scenario that shifts the revenue uncertainty of all firms in the same way.

The second part of the survey levied firm characteristics that determine, according to the theory discussed in Section 2, how strongly a firm responds to uncertainty shocks. Specifically, we collected firms' hiring and firing costs, their labor attrition rate and the resale values for different capital assets. The latter inform about the firm-specific degree of capital irreversibility. The wording of the resale value question was as follows:

Please assume that, due to operational reasons, you will have to sell the investments made in 2017 and 2018 directly after their realization. In your opinion, what will their resale value (net residual value) be?

(as a percentage of the total investments stated above)

$\begin{array}{llll}\text { Real estate } \quad: \% & \text { Intangible assets } \quad \% & \text { Mobile tangible assets }: \ldots \% \\ & \text { (including IT) } & \text { (excluding IT) }\end{array}$

The third part of the survey contained the actual survey experiment. This is described in the following section. 


\subsection{The Hypothetical Vignette}

In a first step, the managers indicated their projections on their respective firm's investment values (in Swiss francs), employment levels (in number of full time equivalents) and production volumes (valued with the current sales prices) for the four subsequent half years. These projections serve as the baseline for the uncertainty shock scenario. Next, the questionnaire reminded the managers of their previously indicated revenue projections for the next year (mean $E_{i, t-1}\left[A_{i, t}\right], 1 \%$-percentile $\underline{Q}_{i, t}$ and $99 \%$-percentile $\bar{Q}_{i, t}$ ). Thereafter, the managers were confronted with a hypothetical vignette according to which the government announces to hold a referendum on a popular initiative. Popular initiatives (or petitions) and referendums are central cornerstone of Switzerland's direct democracy. The former instrument gives Swiss citizens the possibility to propose a law change or a new law. For an initiative to be voted upon in a national referendum, 100'000 signatures (out of approximately 5.5 million voters) must be collected within 18 months. On average over the past ten years, around eight referendums were held every year. Federal referendums address topics that generally have far-reaching consequences for the whole Swiss economy or society. Thus, the scenario described in the vignette is familiar to the survey participants.

The vignette approach allows us to fix the managers' beliefs about the source and duration of the uncertainty shock and to make sure that the managers understand that the shock is truly exogenous, public knowledge and is affecting the whole economy. Specifically, the vignette is designed such that the announcement of the referendum leads to a permanent shift of firms' demand expectations: if the referendum is adopted expectations will shift upwards, if it is rejected expectations will shift downwards. This shift in expectations implies a temporary doubling of each manager's previously indicated revenue uncertainty until the date of the referendum, whereas the previously indicated mean expectation on the revenue is unchanged. To quote the vignette in full: 
At the beginning of April 2017, the Federal Council announces that it will put an initiative to the vote in July 2017 that will have a substantial impact on your future turnover. If the initiative is voted in, the impact on your demand will be positive, if it is rejected the effect will be negative.

Recent polls show that around $50 \%$ of Swiss voters are currently in favour of the initiative. The percentage of voters who reject the initiative is also $50 \%$.

The initiative will affect your long-term expected turnover (net annual turnover in 2018) as follows:

\section{Your new expectations}

if the initiative is accepted

$$
E_{i, t-1}\left[\bar{A}_{i, t}\right]
$$

$\mathrm{CHF}$

if the initiative is rejected

$$
E_{i, t-1}\left[\underline{A}_{i, t}\right]
$$

The online survey tool calculated $E_{i, t-1}\left[\bar{A}_{i, t}\right]$ and $E_{i, t-1}\left[\underline{A}_{i, t}\right]$ such that the standard deviation of each manager's previously indicated firm-specific revenue expectation distribution doubles, whereas the mean expectation revenue $E_{i, t-1}\left[A_{i, t}\right]$ remains equal. Appendix $\mathrm{A}$ discusses this in detail. Specifically, it shows how $E_{i, t-1}\left[\bar{A}_{i, t}\right]$ and $E_{i, t-1}\left[\underline{A}_{i, t}\right]$ are calculated as a function of $E_{i, t-1}\left[A_{i, t}\right], \underline{Q}_{i, t}$ and $\bar{Q}_{i, t}$. As a last step, the managers were asked to update their previously indicated investment, employment and production projections for the four subsequent half years given the information treatment of the vignette. ${ }^{3}$ The effect of this treatment on the firms' beliefs is calculated by the difference between the

\footnotetext{
${ }^{3}$ These are the only repeated questions in the survey, which contains the survey fatigue issue.
} 
updated and the original projections. The differencing cancels out constant individual expectation biases on the future business development and addresses the issue of "coherent arbitrareness", according to which statements about differences are more reliable than statements about levels (Ariely, Loewenstein and Prelec, 2003). ${ }^{4}$

Three things are worth stressing about the above vignette: First, it is a challenge to separate uncertainty shocks (second moment shocks) from mean expectation shocks (first moment shocks), since both usually coincide in reality (e.g., Bloom, 2014). The hypothetical vignette addresses this issue by imposing an exogenous shift in the managers' uncertainty of their expectations, while holding their mean expectations constant. Second, in reality, uncertainty and other macroeconomic shocks hit individual economic agents very differently. Some agents are hit strongly, whereas others are only little affected. This is a challenge if the researcher wants to compare the responsiveness to a macroeconomic shock across individual units: it is difficult to disentangle whether an agent is responding strongly (only weakly) to the shock, because her individual characteristics make her very responsive (not very responsive) to this shock or just because she has been hit strongly (only weakly) by the shock. ${ }^{5}$ To solve this issue, we designed the macroeconomic policy uncertainty shock scenario such that it shifts the pre-existing individual expectation uncertainty of each manager by the same relative amount. Concretely, the standard deviation of each manager's firm-specific revenue expectation distribution gets doubled. Moreover, having levied various firm-level characteristics, we can study which characteristics influence firms' responsiveness to the shock. Third, VAR or DSGE based impulse response studies often carefully analyze the time profile of shock responses. An important question is how long it takes until the effects of a shock peter out. Survey based studies can help answering this question (see, e.g., Coibion, Gorodnichenko and

\footnotetext{
${ }^{4}$ Bloom et al. (2020) find the firm expectations in business surveys to be a reliable measure for actual future outcomes. In contrast, Liu and Palmer (2021) find a systematic gap between individuals' house price projections in consumer surveys and their beliefs used as a basis for actual investment decisions. Further, D'Acunto et al. (2019) study the cognitive abilities of survey respondents and draw conclusions for economic policy.

${ }^{5} \mathrm{~A}$ boxer may go down, because a punch was very hard or because she is not very tough.
} 
Ropele, 2020, who present evidence on the effects of information shocks on the dynamics of pricing and other economic decisions of firm managers). Our vignette contributes here by letting the firm managers assess the effects of the uncertainty shock over four subsequent half years. Thus, we will learn how persistent the effects of the shock are according to the beliefs of the managers.

\section{Empirical Results}

In theoretical models of uncertainty, the real-options channel represents an important mechanism connecting uncertainty and the economy. The central elements of the realoptions channel are, among others, capital and labour adjustment costs. As we already pointed out in Section 2, these parameters heavily influence the effects of uncertainty shocks on investment, employment and production. Even small changes of these parameters can significantly change the effects of uncertainty on the economy. In the following section, we first present our survey evidence on capital and labour adjustment costs and subsequently outline how firms update their investment, employment and production plans when being confronted with an uncertainty shock. We then connect expected firmlevel reactions to firm-level capital and labour adjustment costs and show that these characteristics influence the way firms think about uncertainty shocks.

\subsection{Firm-Level Evidence on Adjustment Costs}

Regardless the importance of capital and labour adjustment costs, the literature offers surprisingly little empirical evidence on the actual values of these adjustment costs. Given this scarcity, we use this section to shed light on the nature of adjustment costs. Using our survey evidence, we provide a comprehensive picture of capital and labour adjustment costs in form of average values, firm-level distributions and correlations. This information might be especially helpful for the calibration of theoretical models. Given the non-linear effects of adjustment costs on the propagation of uncertainty shocks in heterogeneous 
firm models and considering our distributional evidence, we believe that attributing an average value to firms might mask important firm-level heterogeneity in the response to uncertainty shocks. Indeed, similar to the distribution of adjustment costs, also the distribution of firm-level reactions to an uncertainty shock displays a high degree of heterogeneity (see Section 4.2) that can be linked to the heterogeneous distribution of adjustment costs (see Section 4.3).

The following tables and figures summarize firms' investment resale values, hiring costs, firing costs and labor attrition. In the questionnaire, we define the investment resale value as the price that one can obtain from re-selling all investments directly after their realization, in percent of the total costs for purchasing and installing the investments in the first place. Overall, we find an aggregate resale value of $52.8 \%$ (see Table 2). ${ }^{6}$ We aggregate values according to a standard aggregation procedure that we detail in Appendix B. A resale value of $52.8 \%$ implies that reselling the acquired capital immediately after its acquisition causes an average loss of approximately half of its initial costs. However, the resale value varies significantly with firm size, sector and across different types of investment. Firms report an aggregate resale value of $75.3 \%$ for investment concerning real estate, a resale value of $52.4 \%$ for investment in equipment and machinery (tangible assets) and a resale value of $28.5 \%$ for IT-related investment (intangible assets).

The investment resale value also varies across sectors. We find the highest resale value in the consumer service sector $(73.6 \%)$. Other services report the lowest resale value of 24.9\%. Our survey data also reveals that the resale value varies with firm size. Small firms report on average the lowest resale value (37.9\%) and large firm report the highest (53.4\%) resale value. This firm-size dependence is especially pronounced for investment in intangible property and can be found to a lesser extent for investment in tangible

\footnotetext{
${ }^{6}$ In the questionnaire, we differentiate resale values by investment types. That is, we levied the resale values of investment in real property, in machinery and equipment and in intangible property separately. We compute the weighted firm-level average resale values using firm-specific investment shares as weights.
} 
Table 2: Investment Resale Value and Its Components

\begin{tabular}{|c|c|c|c|c|c|c|c|c|}
\hline & \multicolumn{2}{|c|}{$\begin{array}{c}\text { Investment } \\
\text { Resale }\end{array}$} & \multicolumn{2}{|c|}{$\begin{array}{c}\text { Real } \\
\text { Estate }\end{array}$} & \multicolumn{2}{|c|}{$\begin{array}{c}\text { Tangible } \\
\text { Assets }\end{array}$} & \multicolumn{2}{|c|}{$\begin{array}{c}\text { Intangible } \\
\text { Assets }\end{array}$} \\
\hline & $\mu$ & $\sigma$ & $\mu$ & $\sigma$ & $\mu$ & $\sigma$ & $\mu$ & $\sigma$ \\
\hline Whole Economy & 52.8 & 27.7 & 75.3 & 29.9 & 52.4 & 22.3 & 28.5 & 23.4 \\
\hline Manufacturing & 50.0 & 22.5 & 51.2 & 34.2 & 53.0 & 21.7 & 40.8 & 27.3 \\
\hline Construction & 62.0 & 18.5 & 87.9 & 15.4 & 63.6 & 18.5 & 36.2 & 27.4 \\
\hline Consumer Services & 73.6 & 23.6 & 82.0 & 25.3 & 63.6 & 17.9 & 30.7 & 28.8 \\
\hline Business Services & 45.2 & 16.8 & 64.6 & 29.1 & 58.6 & 12.6 & 31.1 & 16.0 \\
\hline Other Services & 24.9 & 22.0 & 65.8 & 35.2 & 26.0 & 15.6 & 12.9 & 10.1 \\
\hline Small & 37.9 & 35.7 & 78.9 & 33.5 & 42.6 & 24.2 & 16.3 & 26.1 \\
\hline Middle & 51.4 & 27.8 & 71.2 & 30.5 & 56.1 & 24.0 & 26.6 & 26.7 \\
\hline Large & 53.4 & 27.6 & 76.2 & 29.7 & 51.5 & 21.5 & 29.2 & 22.3 \\
\hline
\end{tabular}

Notes: $\mu$ represents the aggregate value and $\sigma$ is the aggregate standard deviation. We use the $N A C E$ Rev. 2 - Statistical Classification of Economic Activities to form sector classes. Manufacturing comprises firms classified as C or D. Construction corresponds to sector class F. Consumer Services summarizes firms of letter class G to J. Business Services includes firms operating in sector K to M. Other services summarizes firms of sector $\mathrm{O}$ to $\mathrm{S}$.

property. The resale value for real property does not vary considerably with firm size.

Figure 2 presents the distribution of investment-specific resale values across firms. This figure offers three important insights. First, resale values vary strongly across firms and are not narrowly distributed among an average value. Second, almost all firms report a resale value below its initial costs. Thus, almost all investment projects manifest some degree of irreversibility implying that firms face some resale loss in case of reselling its investment. Finally, the distribution of resale values varies considerably across investment types. With respect to real property, a large fraction of firms report a resale value of $100 \%$ or only slightly below. Thus, a considerable part of real property can be considered as reversible. However, the shape of the distribution changes completely when looking at intangible property. For investment in intangible property, most firms report a resale value of $0 \%$ or only slightly above. Hence, a large fraction of investment in intangible property is fully irreversible. 
Figure 2: Firm-Level Distribution of the Investment Resale Value and Its Components
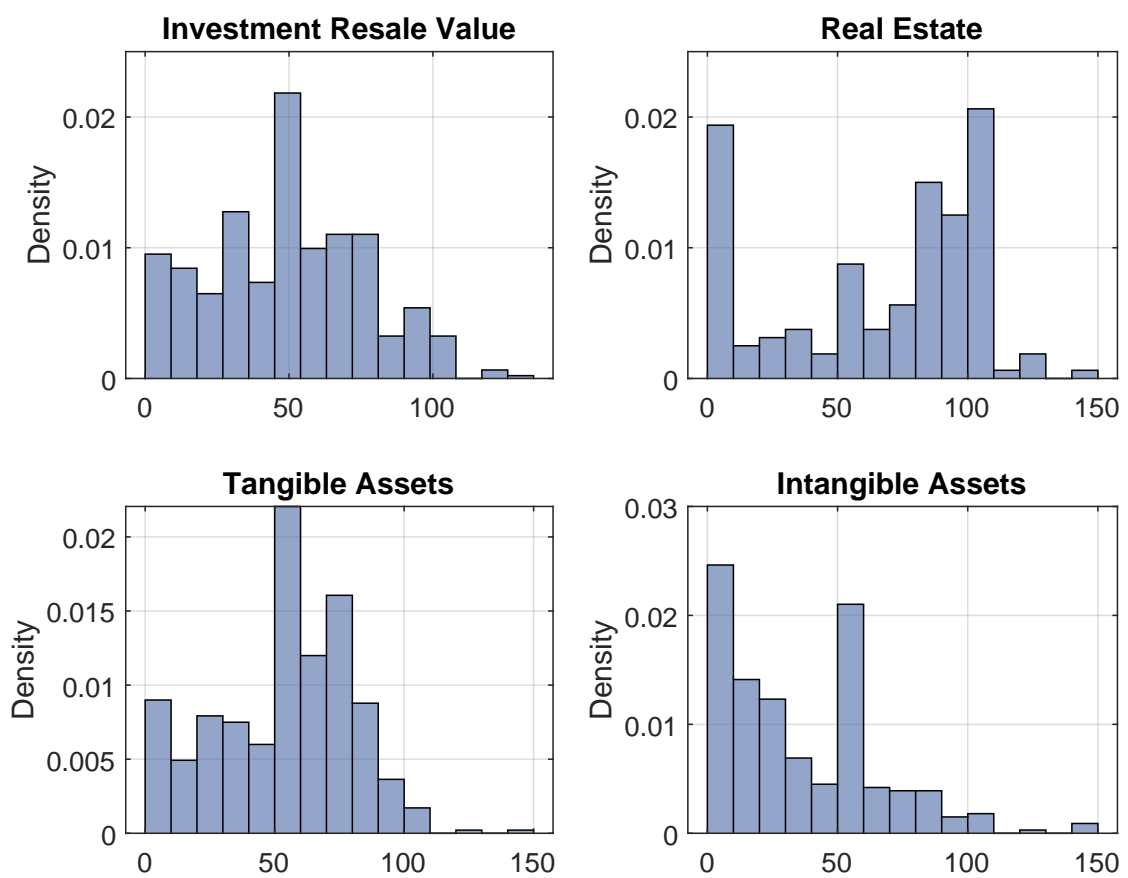

Notes: The figure depicts the firm-level distribution of the investment resale value for Switzerland. More specifically, it shows the value firms' belief to obtain in case they would need to resell their recently acquired capital goods immediately. The upper-right histogram "Investment Resale Value" refers the average resale value over all capital goods. The other histograms display the resale value for specific type of capital goods.

Beside the investment resale value, we also collected firms' firing and hiring costs. We invited firms to state the average costs associated to a statutory dismissal by the employer (including, among others, severance pay, lawyer's or court costs, release from work, reduced working hours) and to state the average cost of recruiting a new full-time employee (including, among others, costs for advertising, recruitment agency, selection process, training, on-the-job training). Firms reported these costs as a percentage of their average annual salary (including additional benefits). Our survey data reveals that hiring a new employee in Switzerland amounts on average to $17.5 \%$ of an annual wage. Firing an employee causes average costs of $9.2 \%$ of an annual wage. Hence, in Switzerland, hiring an employee is on average more costly than firing an employee: hiring costs exceed firing costs on average by roughly $90 \%$ (see Table 3 ). 
Table 3: Capital and Labor Adjustment Costs

\begin{tabular}{|c|c|c|c|c|c|c|c|c|}
\hline & \multicolumn{2}{|c|}{$\begin{array}{l}\text { Investment } \\
\text { Resale }\end{array}$} & \multicolumn{2}{|c|}{$\begin{array}{l}\text { Hiring } \\
\text { Costs }\end{array}$} & \multicolumn{2}{|c|}{$\begin{array}{c}\text { Firing } \\
\text { Costs }\end{array}$} & \multicolumn{2}{|c|}{$\begin{array}{c}\text { Attrition } \\
\text { Rate }\end{array}$} \\
\hline & $\mu$ & $\sigma$ & $\mu$ & $\sigma$ & $\mu$ & $\sigma$ & $\mu$ & $\sigma$ \\
\hline Whole Economy & 52.8 & 27.7 & 17.5 & 20.7 & 9.2 & 16.1 & 10.3 & 7.6 \\
\hline Manufacturing & 50.0 & 22.5 & 19.5 & 25.8 & 10.4 & 20.7 & 8.1 & 5.4 \\
\hline Construction & 62.0 & 18.5 & 25.3 & 17.1 & 7.7 & 11.4 & 9.0 & 4.2 \\
\hline Consumer Services & 73.6 & 23.6 & 17.2 & 24.2 & 7.8 & 17.7 & 11.9 & 9.4 \\
\hline Business Services & 45.2 & 16.8 & 23.1 & 12.0 & 10.0 & 8.0 & 12.3 & 5.7 \\
\hline Other Services & 24.9 & 22.0 & 5.3 & 8.4 & 10.8 & 12.1 & 5.5 & 5.1 \\
\hline Small & 37.9 & 35.7 & 16.4 & 23.6 & 6.8 & 9.1 & 7.4 & 6.6 \\
\hline Middle & 51.4 & 27.8 & 17.7 & 26.7 & 9.2 & 17.2 & 8.4 & 6.0 \\
\hline Large & 53.4 & 27.6 & 17.4 & 17.7 & 9.1 & 15.5 & 11.1 & 8.1 \\
\hline
\end{tabular}

Notes: $\mu$ represents the aggregate value and $\sigma$ is the aggregate standard deviation. We use the $N A C E$ Rev. 2 - Statistical Classification of Economic Activities to form sector classes. Manufacturing comprises firms classified as C or D. Construction corresponds to sector class F. Consumer Services summarizes firms of letter class G to J. Business Services includes firms operating in sector K to M. Other services summarizes firms of sector $\mathrm{O}$ to $\mathrm{S}$.

While this relationship holds qualitatively true for (almost) every sector, labor adjustment costs vary across sectors. We find the highest relative hiring costs in the construction sector and business service sector. Firms from sector "Other Services" display lowest relative hiring and highest relative firing costs. In Figure 3, we present the firm-level distributions of hiring and firing costs. Both distributions are strongly skewed to the right and show that the largest mass of hiring and firing costs lies between $0 \%$ and $20 \%$ of an annual wage. However, a small share of firms reports hiring and firing costs of $75 \%$ and above. With respect to firm size, we find evidence that large firms face on average smaller relative hiring and firing costs.

Finally, we also levied information about firms' labor attrition. Specifically, we asked firms about their average fluctuation rate (including voluntary departures and retirement) over the last few years. The average annual fluctuation rate amounts to $10.3 \%$ 
implying that on average $10.3 \%$ of all employees voluntarily leave the company within a year. We find the highest attrition rate for firm's in the Business Service Sector with an average fluctuation of $12.3 \%$. Firms from the sector class Other Services experience the lowest fluctuation rate with $5.5 \%$. The fluctuation rate increases with firm size. Smaller firms report on average a lower attrition rate (7.4\%) than large firms $(11.1 \%)$.

Figure 3: Firm-Level Distribution of Capital and Labor Adjustment Costs
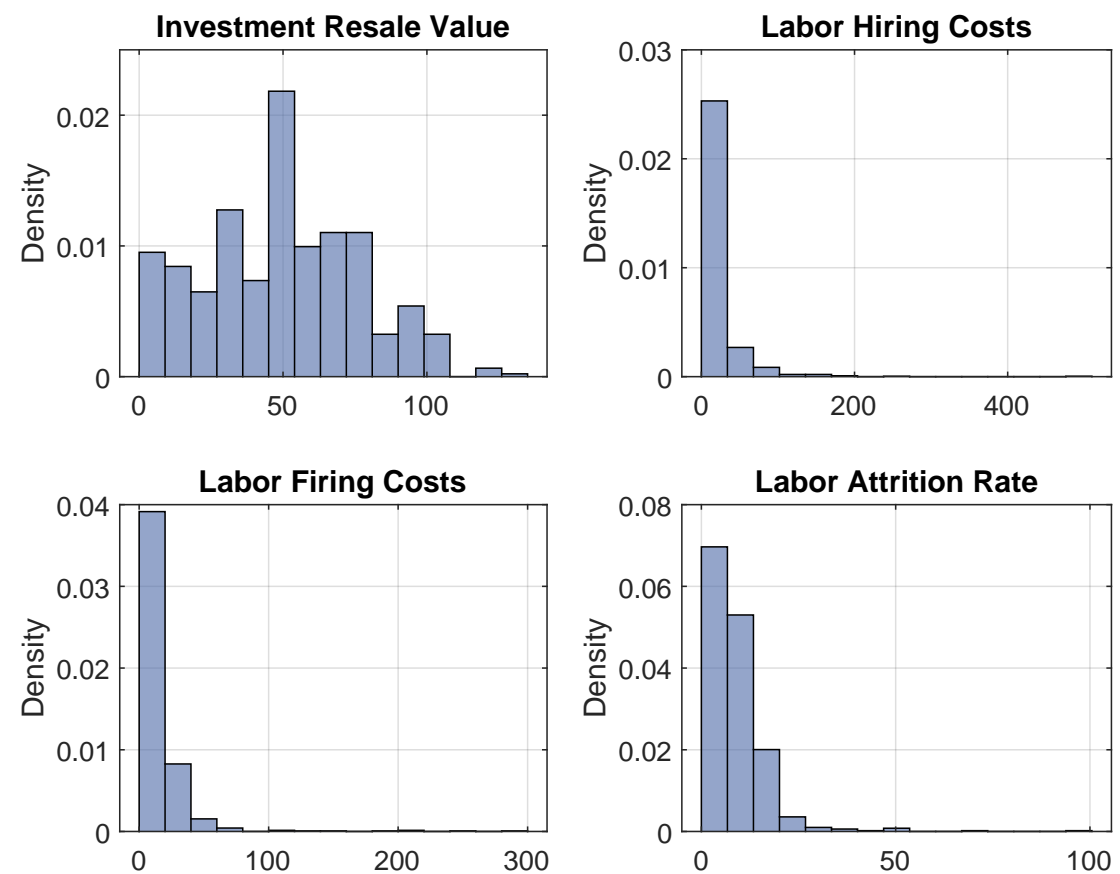

Notes: The figure depicts the firm-level distribution of the investment resale value, hiring and firing costs, and labor attrition for Switzerland.

Our survey data allows us to study also the correlation of adjustment costs at the firmlevel. Table 4 provides an overview of these correlations. Overall, we find that firms' resale values and labor attrition rates do not display a strongly correlation with other firm characteristics. However, in comparison to resale value and labor attribution, we find a positive correlation between firm-level firing and hiring costs. This correlation is especially high for large firms and decreases with firm size. The firm-level attrition rate appears to be uncorrelated with labor or capital adjustment costs. 
Table 4: Correlation Across Adjustment Costs

\begin{tabular}{lcccccc}
\hline \hline & $\begin{array}{c}\text { Resale } \\
\text { vs. } \\
\text { Hiring }\end{array}$ & $\begin{array}{c}\text { Resale } \\
\text { vs. } \\
\text { Firing }\end{array}$ & $\begin{array}{c}\text { Resale } \\
\text { vs. } \\
\text { Attrition }\end{array}$ & $\begin{array}{c}\text { Hiring } \\
\text { vs. } \\
\text { Firing }\end{array}$ & $\begin{array}{c}\text { Hiring } \\
\text { vs. } \\
\text { Attrition }\end{array}$ & $\begin{array}{c}\text { Firing } \\
\text { vs. } \\
\text { Attrition }\end{array}$ \\
\cline { 2 - 7 } Whole Economy & -0.03 & 0.04 & -0.04 & 0.40 & 0.07 & 0.05 \\
Manufacturing & 0.01 & 0.14 & 0.01 & 0.34 & 0.14 & 0.06 \\
Construction & 0.11 & 0.08 & -0.17 & 0.74 & -0.07 & -0.10 \\
Consumer Services & -0.30 & -0.13 & -0.14 & 0.44 & 0.07 & 0.09 \\
Business Services & 0.14 & -0.18 & -0.02 & 0.29 & 0.02 & 0.14 \\
Other Services & 0.22 & -0.07 & 0.10 & 0.21 & 0.09 & 0.08 \\
Small & -0.03 & -0.09 & -0.09 & 0.34 & 0.02 & 0.08 \\
Middle & -0.05 & 0.07 & -0.07 & 0.35 & 0.06 & 0.03 \\
Large & 0.02 & -0.07 & 0.04 & 0.61 & 0.15 & 0.15 \\
\hline \hline
\end{tabular}

Notes: Resale represents the investment resale value, hiring and firing are the labor hiring costs and labor firing costs, respectively, and attrition is the labor attrition rate. We use the NACE Rev. 2 - Statistical Classification of Economic Activities to form sector classes. Manufacturing comprises firms classified as $\mathrm{C}$ or D. Construction corresponds to sector class F. Consumer Services summarizes firms of letter class $\mathrm{G}$ to J. Business Services includes firms operating in sector K to M. Other services summarizes firms of sector $\mathrm{O}$ to $\mathrm{S}$.

Table 5 compares our survey evidence of capital and labor adjustment costs to other estimates found in the literature. While we are the first to directly measure investment resale values, several studies present estimates of investment resale values. Overall, the literature offers a wide range of values. Ramey and Shapiro (2001) place the investment resale value somewhere between $20 \%$ and $60 \%$ of the initial costs. Cooper and Haltiwanger (2006) find a resale value of 97.5\%, implying a very low resale loss in case a firm resells its capital. Bloom (2009) estimates a firm model using simulated methods of moments and finds an investment resale value of 66.1\%. Gilchrist, Sim and Zakrajšek (2014) calibrate the resale value in their model to $50 \%$ by using the estimated book-value of total debt from quarterly Compustat data from 1976:Q1 to 2012:Q3. Khan and Thomas (2013) and Lanteri (2018) use resale values of 95.4\% and 93.3\%. The high heterogeneity of resale values (Figure 2) uncovered by our survey offers a possible explanation for this broad range of estimates. Depending on what type of capital or what kind of sector one includes in the analysis, one might find a different resale value. This underpins the argu- 
ment that when modelling uncertainty shocks in heterogeneous agent models one might profit from introducing heterogeneity in resale values instead of equipping all firms with an average value.

Table 5: Literature Comparison of Adjustment Costs

\begin{tabular}{lccccc}
\hline \hline & Country & $\begin{array}{c}\text { Resale } \\
\text { Value }\end{array}$ & $\begin{array}{c}\text { Firing } \\
\text { Costs }\end{array}$ & $\begin{array}{c}\text { Hiring } \\
\text { Costs }\end{array}$ & $\begin{array}{c}\text { Fixed Labor } \\
\text { Adjustment }\end{array}$ \\
\hline Ramey and Shapiro (2001) & USA & $20-60 \%$ & & & \\
Cooper and Haltiwanger (2006) & USA & $97.5 \%$ & & & \\
Bloom (2009) / Bloom et al. (2018) & USA & $66.1 \%$ & $1.8 \%$ & $1.8 \%$ & $2.1 \%$ \\
Gilchrist, Sim and Zakrajšek (2014) & USA & $50 \%$ & & & \\
Khan and Thomas (2013) & USA & $95.4 \%$ & & & \\
Lanteri (2018) & USA & $93.3 \%$ & & & \\
Nickell (1986) & USA & & $1-4 \% / 4-24 \%$ & \multirow{2}{*}{$1.7 \%$} \\
Cooper, Haltiwanger and Willis (2007) & USA & & & & \\
Del Boca and Rota (1998) ${ }^{2}$ & ITA & & $17-22 \%$ & $4-167 \%$ & \\
Freyens and Oslington (2007) & AUS & & $10.3-17.1 \%$ & & \\
This Paper: Overall & CHE & $52.8 \%$ & $9.2 \%$ & \multirow{2}{*}{$17.5 \%$} & \\
This Paper: Real property & CHE & $75.3 \%$ & & & \\
This Paper: Intangible property & CHE & $28.5 \%$ & & & \\
This Paper: Tangible property & CHE & $52.4 \%$ & & & \\
\hline \hline
\end{tabular}

1 Nickell (1986) reports hiring and firing costs intervals for blue-collar and white-collar workers.

${ }^{2}$ Del Boca and Rota (1998) report minimum and maximum values.

3 The values by Freyens and Oslington (2007) refer to uncontested dismissal (lower value) and unfair and average conciliation and settlement costs if a dismissal for cause is contested as being Conciliation and settlement costs average (upper value).

Compared to capital adjustment costs, some more studies exist that focus on quantifying hiring and firing costs. However, while several studies approximate labor adjustment costs by focusing on the legal framework of a country, studies directly quantifying hiring and firing costs are equally scarce. For the U.S., Bloom (2009) estimates a firm-level model using simulated method of moments and finds average hiring and firing costs of $1.8 \%$ of an annual wage. Del Boca and Rota (1998) conduct a survey among Italian manufacturing firms to study firing costs. They report firing costs that range from less than half a monthly (3.6\% of an annual wage bill) of labour cost to up to 20 months of labour costs (166\% of an annual wage bill) in cases of a conflict. Freyens and Oslington 
(2007) conduct a survey among small firms in Australia and find average firing costs of $10.3 \%$ in case of an uncontested dismissal and $17.7 \%$ in case a dismissal is contested.

\subsection{Heterogeneity in Beliefs}

In our survey, we first levied firms' expected investment, employment and production over the next two years on a semi-annual frequency. Next, we informed the firm managers about a macroeconomic policy shock that translates into an increase in uncertainty about future demand (see Section 3). We then ask them to update their investment, employment and production plans by taking into account the newly obtained information. This setting allows us to observe how firms' update their beliefs about investment, employment and production plans. Moreover, the structure of the survey question allows us to compute the change of firms' semi-annual investment, production or employment plans in response to the shock. This firm-level reaction can be expressed as follows:

$$
\delta_{i, h}=\frac{E_{i, t}\left[Y_{i, t+h} \mid \eta_{t}=1\right]-E_{i, t}\left[Y_{i, t+h} \mid \eta_{t}=0\right]}{E_{i, t}\left[Y_{i, t+h} \mid \eta_{t}=0\right]},
$$

where $E_{i, t}\left[Y_{i, t+h}\right]$ is the expectation of the manager of firm $i \in\{1, \ldots, n\}$ in period $t$ on the level $Y_{i, t+h}$ of either investment, employment or real output in period $t+h, \eta_{t}$ is a treatment variable with $\eta_{t}=0$ before the managers are confronted with the uncertainty shock scenario and with $\eta_{t}=1$ after they are confronted with shock scenario, $\delta_{i, h}$ is firm $i$ 's planned change in investment, production or employment $h$ half-years after the shock, where $h \in\{1,2,3,4\}$.

We summarize $\delta_{i, h}$ in Figure 4 to 6 and in Table 6 . Figures 4 to 6 present the entire distribution of the expected changes for investment, employment and production and Table 6 summarizes firm behavior in a more concise manner. This overview offers valuable insights. First, firms differ substantially in their beliefs about how they would react to an uncertainty shock. Second, the largest share of firms does not react to the uncer- 
tainty shock. Table 6 shows that more than half of all firms state that they would not adjust their plans. Third, firms do not react immediately. On the contrary, for all three variables, the share of firms that report no reaction decreases over time implying that the share of reacting firms increases over time. Thereby, both the share of firms that increase and the share of firms that decrease their plans increases over time. Finally, in contrast to employment and production, a significant share of firms $(>10 \%)$ states that they plan to completely pause or cancel their investment projects given the new information. This highlights that, in contrast to employment and production, the response in aggregate investment is like to be driven by a fraction of firms that completely cuts back their investment. In the following section, we will further examine the heterogeneity in responses and examine possible correlation with firm characteristics.

Figure 4: Firm-Level Distribution of Investment Responses
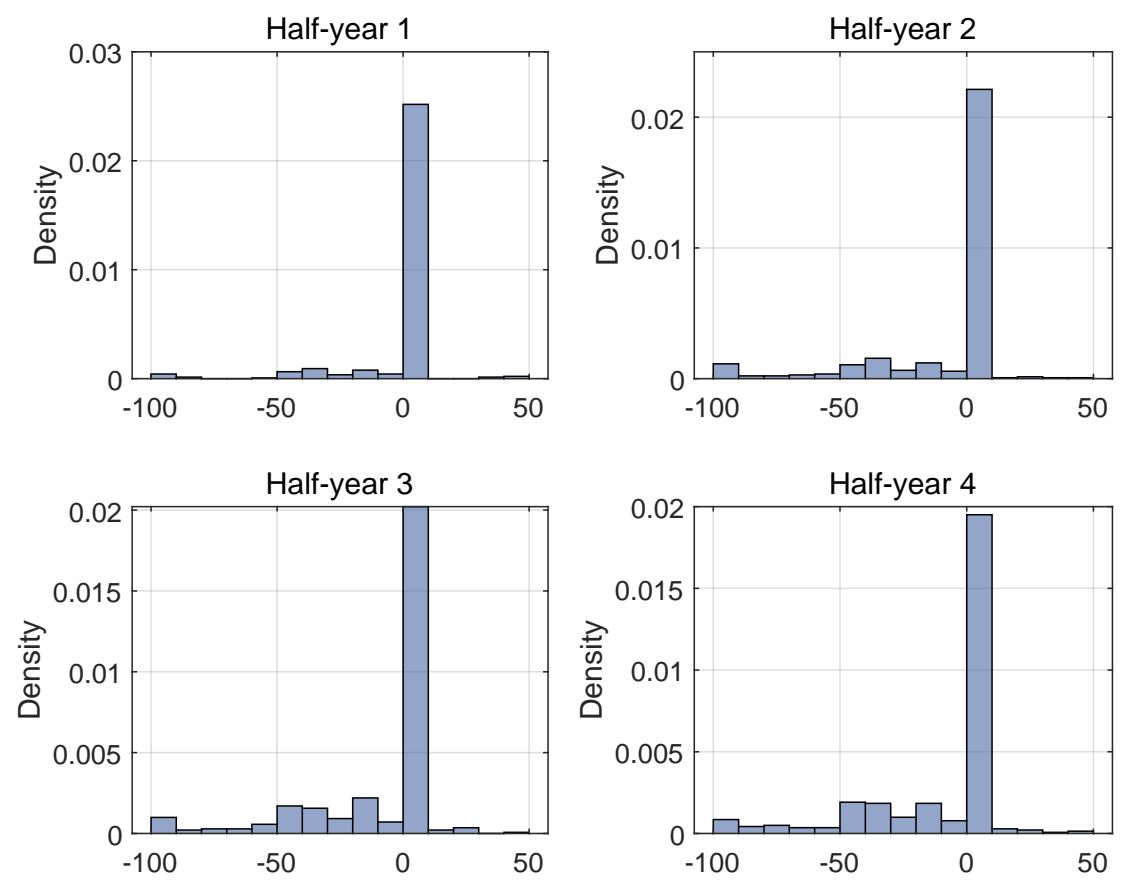

Notes: Each graph depicts firms' responses (in \%) $h$ half-years after a one standard deviation uncertainty shock, where $h \in\{2,4,6,8\}$. 
Figure 5: Firm-Level Distribution of Employment Responses
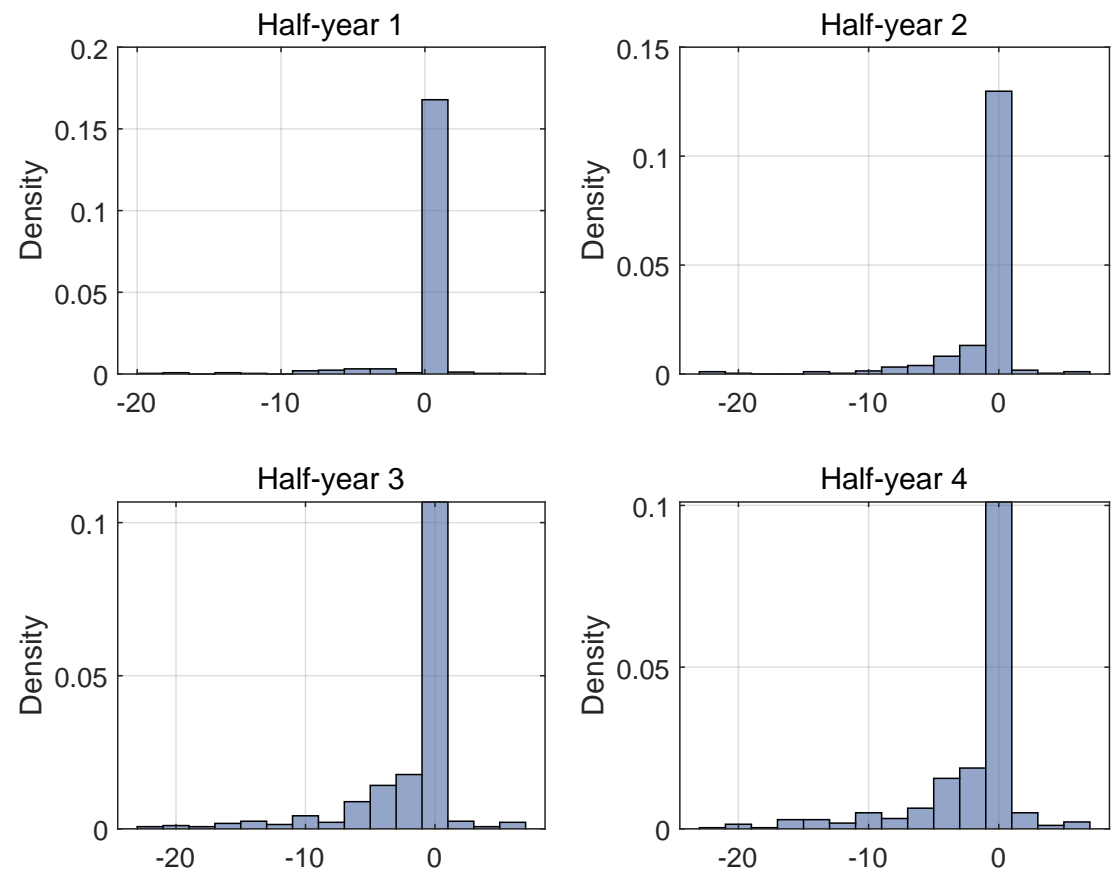

Notes: Each graph depicts firms' responses (in \%) $h$ half-years after a one standard deviation uncertainty shock, where $h \in\{2,4,6,8\}$.

Figure 6: Firm-Level Distribution of Real Output Responses
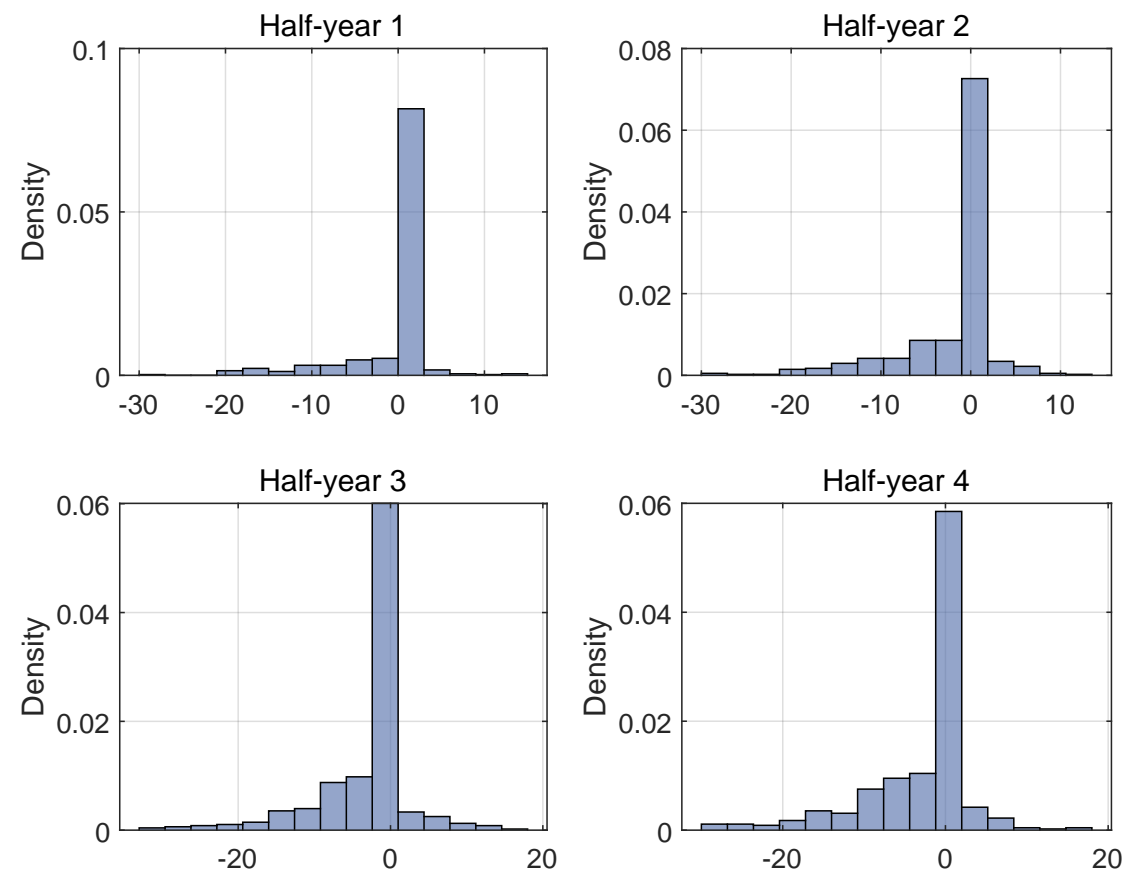

Notes: Each graph depicts firms' responses (in \%) $h$ half-years after a one standard deviation uncertainty shock, where $h \in\{2,4,6,8\}$. 
Table 6: Firm Reactions to Uncertainty Shock

\begin{tabular}{|c|c|c|c|c|c|}
\hline & & Half-Year 1 & Half-Year 2 & Half-Year 3 & Half-Year 4 \\
\hline 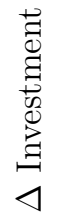 & $\begin{array}{l}>0 \% \\
=0 \% \\
<-20 \% \\
=-100 \%\end{array}$ & $\begin{array}{c}0 \% \\
78.8 \% \\
17.3 \% \\
10.1 \%\end{array}$ & $\begin{array}{c}0.5 \% \\
68.4 \% \\
25.6 \% \\
11.8 \%\end{array}$ & $\begin{array}{c}1.1 \% \\
61.9 \% \\
28.3 \% \\
10.9 \%\end{array}$ & $\begin{array}{c}1.3 \% \\
59.7 \% \\
31.1 \% \\
11.4 \%\end{array}$ \\
\hline 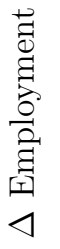 & $\begin{array}{l}>0 \% \\
=0 \% \\
<-20 \% \\
=-100 \%\end{array}$ & $\begin{array}{c}1.5 \% \\
89.9 \% \\
1.5 \% \\
1.1 \%\end{array}$ & $\begin{array}{c}3.0 \% \\
74.1 \% \\
1.9 \% \\
0.9 \%\end{array}$ & $\begin{array}{c}4.6 \% \\
60.0 \% \\
2.5 \% \\
1.0 \%\end{array}$ & $\begin{array}{c}6.0 \% \\
55.6 \% \\
2.9 \% \\
1.0 \%\end{array}$ \\
\hline 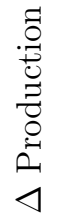 & $\begin{array}{l}>0 \% \\
=0 \% \\
<-20 \% \\
=-100 \%\end{array}$ & $\begin{array}{c}4.9 \% \\
73.3 \% \\
1.8 \% \\
1.1 \%\end{array}$ & $\begin{array}{c}6.7 \% \\
60.5 \% \\
3.8 \% \\
1.3 \%\end{array}$ & $\begin{array}{c}9.1 \% \\
51.9 \% \\
4.2 \% \\
1.1 \%\end{array}$ & $\begin{array}{c}8.8 \% \\
51.2 \% \\
4.8 \% \\
1.1 \%\end{array}$ \\
\hline
\end{tabular}

Notes: This table summarizes the believed reaction of firms to an uncertainty shock. The table presents the percentage of firms that believe that their investment, employment and production increases, remains unchanged, decreases by less than $20 \%$ or decreases by $100 \%$ after an uncertainty shocks.

\subsection{Transmission Channels at the Firm Level}

There exists a large heterogeneity at the firm level in how strongly the uncertainty shock affects investment, output and employment according to the beliefs of the firm managers. Some firms project to reduce their activity strongly in response to the shock, whereas others expect only minor effects. According to the real-options channel of investment, this heterogeneity can be explained by differences in capital and labor adjustments costs across firms. In this section, we study the relevance of different types of adjustments costs by means of a firm-level regression analysis. 
Consider the following regression model:

$$
\delta_{i, h}=\boldsymbol{d}^{\prime} \boldsymbol{\alpha}+\boldsymbol{x}_{i}^{\prime} \boldsymbol{\beta}+\boldsymbol{z}_{i}^{\prime} \boldsymbol{\gamma}+\epsilon_{i, h}
$$

$\delta_{i, h}$ is firm $i$ 's planned change in investment, production or employment (in \%) in response to the uncertainty shock $h$ half-years after the shock, where $i \in\{1, \ldots, n\}$ and $h \in\{1,2,3,4\}$. We trim $\delta_{i, h}$ at the 1st and 99th percentile to ensure that our results are not driven by outliers. ${ }^{7} \boldsymbol{d}$ is a vector of 4 horizon dummies, where the $h$-th dummy takes value 1 for horizon $h$ and zero otherwise. $\boldsymbol{\alpha}$ is the corresponding vector of horizon-specific intercepts. $\boldsymbol{x}_{i}$ is a vector of firm-specific explanatory variables and $\boldsymbol{\beta}$ is the attached vector of coefficients. $\boldsymbol{z}_{i}$ is a vector of industry dummies, where the $k$-th dummy takes value 1 if firm $i$ is in industry $k$ and zero otherwise. $\gamma$ is the corresponding vector of industry-specific fixed effects that control for unobserved heterogeneity between industries. Canton-specific fixed effects are included in the same way to capture unobserved regional disparities. The regression coefficients are estimated by ordinary least squares.

Table 7 shows the regression results including horizon-specific intercepts only. On average over all firms, the managers expect the level of investment to be $4.0 \%(9.1 \%, 10.5 \%$, $12.0 \%$ ) lower in the first (second, third, fourth) half-year after the shock as compared to their no-shock projections (see column 1). The employment level in the first (second, third, fourth) half-year after the shock is, on average, expected to be $0.4 \%(0.9 \%, 1.5 \%$, $1.7 \%$ ) lower relative to the no-shock projections. Further, the level of real output is projected to be $1.3 \%(1.8 \%, 2.1 \%, 2.2 \%)$ lower one (two, three, four) half-years after shock. Comparing across columns, the negative effects on real output, and especially on employment, are much weaker than the negative investment effects according to the beliefs of the firm managers. The expected negative growth effects on investment gradually peter out half a year after the end of the uncertainty shock (i.e. at the third half-yearly hori-

\footnotetext{
${ }^{7}$ The robustness checks below present the regressions without trimming of the dependent variables.
} 
zon). In contrast, the negative growth effects on employment and output are more long lasting: they gradually phase out one year after the end of the shock (i.e. at the fourth half-yearly horizon). It is noteworthy that for none of the variables the managers expect catch-up effects back to the no-shock levels, at least not during the considered horizons. Note further that for all three variables, the reported average effects are different from the aggregate effects discussed in Section 4.4. In particular, for investment the average effects are substantially more negative than the aggregate effects. This shows the value of having a representative sample and aggregating with appropriate firm and industry weights (see Appendix B).

Table 7: Baseline Regressions

\begin{tabular}{lccc}
\hline \hline & $(1)$ & $(2)$ & $(3)$ \\
& Investment & Employment & Real Output \\
\hline 1-half-year horizon intercept & $-4.014^{* * *}$ & $-0.434^{* * *}$ & $-1.288^{* * *}$ \\
& $(1.111)$ & $(0.148)$ & $(0.247)$ \\
2-half-year horizon intercept & $-9.096^{* * *}$ & $-0.865^{* * *}$ & $-1.822^{* * *}$ \\
& $(1.111)$ & $(0.148)$ & $(0.247)$ \\
3-half-year horizon intercept & $-10.460^{* * *}$ & $-1.530^{* * *}$ & $-2.120^{* * *}$ \\
& $(1.111)$ & $(0.148)$ & $(0.247)$ \\
4-half-year horizon intercept & $-12.008^{* * *}$ & $-1.741^{* * *}$ & $-2.243^{* * *}$ \\
& $(1.111)$ & $(0.148)$ & $(0.247)$ \\
Industry-specific dummies & No & No & No \\
Canton-specific dummies & No & No & No \\
\hline Observations & 1,516 & 1,768 & 1,708 \\
Adjusted $\mathrm{R}^{2}$ & 0.157 & 0.138 & 0.121 \\
\hline \hline
\end{tabular}

Notes: Dependent variable: Firm manager's expected change in investment/employment/real output in response to uncertainty shock relative to noshock scenario. Standard errors in parentheses. ${ }^{*} \mathrm{p}<0.1 ;{ }^{* *} \mathrm{p}<0.05 ;{ }^{* * *} \mathrm{p}<0.01$.

Table 8 adds our variables of interest in addition to the horizon-specific intercepts. We now also include industry and canton dummies and control for firm size as proxied by the firms' revenue. The investment resale value is defined as the price that can be obtained from re-selling all investments directly after their realization, in percent of the total costs 
for purchasing and installing the investments in the first place. The labor adjustment costs are proxied by the total costs that result, on average, from hiring or dismissing a full-time employee, in percent of the average gross yearly salary of a full-time employee in the firm. The attrition rate is defined as the average labor turnover (including voluntary exits and retirements) in percent of the total number of employees. The initial revenue uncertainty is captured by the difference between the firm managers' $99 \%$ - and 1\%-percentile net turnover expectations for the next year, in percent of the mean expectation. We include this variable to control for possible non-linear effects: the firm managers' expected effect of the uncertainty shock might dependent on the initial firm-specific level of uncertainty. However, it turns out that this is mostly not the case. Note that all control variables are pre-shock variables, i.e. they are collected before confronting the firm managers with the shock scenario. Appendix E records the variables in their original formulation.

Table 8: Regressions With Capital and Labor Adjustment Costs

\begin{tabular}{lccc}
\hline \hline & $(1)$ & $(2)$ & $(3)$ \\
& Investment & Employment & Real Output \\
\hline Investment resale value & $0.095^{* * *}$ & 0.0003 & $0.017^{* *}$ \\
& $(0.030)$ & $(0.003)$ & $(0.007)$ \\
Labor adjustment costs & $-0.077^{* *}$ & $-0.010^{* *}$ & -0.006 \\
& $(0.037)$ & $(0.004)$ & $(0.008)$ \\
Labor attrition rate & -0.032 & $0.043^{* * *}$ & $0.064^{* *}$ \\
Initial revenue uncertainty & $(0.110)$ & $(0.013)$ & $(0.026)$ \\
& -0.047 & -0.015 & -0.041 \\
Firm size & $(0.136)$ & $(0.016)$ & $(0.031)$ \\
& 0.000 & 0.000 & -0.000 \\
Horizon-specific intercepts & $(0.000)$ & $(0.000)$ & $(0.000)$ \\
Industry-specific dummies & Yes & Yes & Yes \\
Canton-specific dummies & Yes & Yes & Yes \\
\hline Observations & 1,096 & 1,196 & Yes \\
Adjusted R ${ }^{2}$ & 0.293 & 0.412 & 1,172 \\
\hline \hline
\end{tabular}

Notes: Dependent variable: Firm manager's expected change in investment/employment/real output in response to uncertainty shock relative to noshock scenario. Standard errors in parentheses. ${ }^{*} \mathrm{p}<0.1 ;{ }^{* *} \mathrm{p}<0.05 ;{ }^{* * *} \mathrm{p}<0.01$. 
As can be seen from column 1 of Table 8, the variation in capital and labor adjustment costs across firms indeed helps to explain why some managers expect the uncertainty shock to have relatively strong negative effects on their firm investments, whereas others expect only relatively weak effects. When the investment resale value (labor adjustment cost) is one standard deviation lower (higher) ceteris paribus, the expected investment drop in response to the shock amplifies by $0.095 \cdot 27.6=2.6(0.077 \cdot 26.8=2.1)$ percentage points. Column 2 shows the results for the expected effects of the uncertainty shock on employment. The investment resale value turns out to have no effect on employment. In contrast, higher labor adjustment costs significantly amplify the drop in employment in response to the shock, according to the beliefs of the managers. Further, the marginal effect of the labor attrition rate variable turns out positive and statistically significant at conventional levels, hence, a higher labor attrition reduces the drop in employment. Column 3 presents the results for the expected effects of the uncertainty shock on real output. The investment resale value and the labor attrition rate turn to matter in terms of economic and statistical significance. In contrast, the marginal effect of the adjustment costs variable is not different from zero at conventional levels of significance, while keeping its negative sign.

Table 9 additionally adds an interaction term between the labor adjustment costs and the labor attrition rate. The marginal effect of this interaction should be positive. The argument here is that higher labor adjustment costs limit a firm's flexibility less if the labor attrition is high anyway. As a consequence, uncertainty shocks should have less impact. We find evidence that this channel is indeed relevant for firms' expected employment and real output responses to the uncertainty shock (see columns 2 and 3). Note also the attrition rate variable itself now is statistically insignificant. This suggests that the labor attrition channel mutes or amplifies the labor adjustment cost channel, rather than being an independent channel. 
Table 9: Regressions With Interaction Term

\begin{tabular}{lccc}
\hline \hline & $(1)$ & $(2)$ & $(3)$ \\
& Investment & Employment & Real Output \\
\hline Investment resale value & $0.098^{* * *}$ & 0.0004 & $0.016^{* *}$ \\
Labor adjustment costs & $(0.030)$ & $(0.003)$ & $(0.007)$ \\
& $-0.190^{* *}$ & $-0.037^{* * *}$ & $-0.031^{* *}$ \\
Labor attrition rate & $(0.085)$ & $(0.010)$ & $(0.012)$ \\
& -0.181 & 0.007 & 0.033 \\
Labor adjustment costs $\times$ attrition rate & $(0.150)$ & $(0.018)$ & $(0.029)$ \\
& 0.012 & $0.003^{* * *}$ & $0.002^{* * *}$ \\
Initial revenue uncertainty & $(0.008)$ & $(0.001)$ & $(0.001)$ \\
Firm size & -0.062 & -0.012 & -0.043 \\
& $(0.136)$ & $(0.016)$ & $(0.031)$ \\
Horizon-specific intercepts & 0.000 & 0.000 & -0.000 \\
Industry-specific dummies & $(0.000)$ & $(0.000)$ & $(0.000)$ \\
Canton-specific dummies & Yes & Yes & Yes \\
\hline Observations & Yes & Yes & Yes \\
Adjusted R ${ }^{2}$ & Yes & Yes & Yes \\
\hline \hline
\end{tabular}

Notes: Dependent variable: Firm manager's expected change in investment/employment/real output in response to uncertainty shock relative to no-shock scenario. Standard errors in parentheses. ${ }^{*} \mathrm{p}<0.1{ }^{* *} \mathrm{p}<0.05 ;{ }^{* * *} \mathrm{p}<0.01$.

Table 10 iterates the regression from Table 8, but with a distinction between hiring and firing costs. The hiring (firing) costs are measured by the total costs that result, on average, from hiring (dismissing) a full-time employee, in percent of the average gross yearly salary of a full-time employee in the firm. As turns out, the firing costs tend to matter more than the hiring costs. In the investment regression of column 1 , the marginal effect of the firing costs is significant at the $12 \%$-level of statistical significance and is more negative than the marginal effect of the hiring cost variable. The same holds true for the employment regression in column 2 .

For robustness, we rerun the regressions with winsorizing instead of trimming the dependent variables at the 1st and 99th percentile. Next, we run the regressions without 
Table 10: Regressions With Differentiation of Firing and Hiring Costs

(1)

$(2)$

(3)

Investment Employment Real Output

\begin{tabular}{lccc}
\hline Investment resale value & $0.089^{* * *}$ & 0.003 & $0.017^{* *}$ \\
& $(0.030)$ & $(0.003)$ & $(0.007)$ \\
Firing costs & -0.047 & $-0.009^{* * *}$ & 0.005 \\
Hiring costs & $(0.030)$ & $(0.004)$ & $(0.007)$ \\
& -0.032 & -0.00003 & -0.007 \\
Labor attrition rate & $(0.032)$ & $(0.004)$ & $(0.007)$ \\
& -0.046 & $0.039^{* * *}$ & $0.071^{* * *}$ \\
Initial revenue uncertainty & $(0.110)$ & $(0.013)$ & $(0.026)$ \\
& 0.159 & -0.020 & $-0.089^{* * *}$ \\
Firm size & $(0.139)$ & $(0.016)$ & $(0.033)$ \\
& 0.000 & 0.000 & -0.000 \\
Horizon-specific intercepts & $(0.000)$ & $(0.000)$ & $(0.000)$ \\
Industry-specific dummies & Yes & Yes & Yes \\
Canton-specific dummies & Yes & Yes & Yes \\
\hline Observations & 1,060 & 1,156 & Yes \\
Adjusted R & & 0.399 & 1,136 \\
\hline \hline
\end{tabular}

Notes: Dependent variable: Firm manager's expected change in investment/employment/real output in response to uncertainty shock relative to noshock scenario. Standard errors in parentheses. ${ }^{*} \mathrm{p}<0.1 ;{ }^{* *} \mathrm{p}<0.05 ;{ }^{* *} \mathrm{p}<0.01$.

trimming or winsorizong at all. Further, we balance the data sample over the three regression columns. This is to check whether differences in results across columns are driven by changes in the sample composition. For all alternative specifications, our findings remain intact. Appendix $\mathrm{C}$ reports the the robustness regressions.

To sum up, the regression analysis provides micro-level evidence that the firm-specific degree of investment and labor irreversibility is important for how strongly an uncertainty shock affects a firm's investment, employment and production plans according to the beliefs of the firm's manager. To the best of our knowledge, this is the first study to deliver such evidence. 


\subsection{Representative Effects}

The beauty of survey responses lies in the fact that there are no assumptions needed on firm managers' degree of rationality. The expectation formation mechanism is taken as given and may vary across managers. Aggregating firms' exptected reactions to a hypothetical uncertainty shock can shed light on managers' ability to anticipate possible feedback loops. ${ }^{8}$ For this purpose, we build weighted averages over the representative firm sample. These can be expressed as

$$
\delta_{h}=\frac{\sum_{i}^{n} \omega_{i} E_{i, t}\left[Y_{i, t+h} \mid \eta_{t}=1\right]-\sum_{i}^{n} \omega_{i} E_{i, t}\left[Y_{i, t+h} \mid \eta_{t}=0\right]}{\sum_{i}^{n} \omega_{i} E_{i, t}\left[Y_{i, t+h} \mid \eta_{t}=0\right]}
$$

where $\omega_{i}$ are firm-specific aggregation weights and where all other variables have already been defined for Equation (3). Appendix B provides a detailed description of the aggregation procedure. We then compare these representative expectations on the effects of the hypothetical uncertainty shock to impulse responses computed from a partial and a general equilibrium version of the Bloom et al. (2018) model described in Section 2 as well as to VAR impulse responses. ${ }^{9}$ Note that, since managers project the effects of the shock for multiple horizons, we are able to analyze the impact and the dynamics of the expected responses.

According to Figure 7, the trajectory of the survey based responses (red lines) are closer to the impulse responses obtained from the general equilibrium model (purple lines) than to those computed from the partial equilibrium model (green lines). The partial equilibrium model produces impulse responses that exhibit the well-known drop-rebound-overshoot

\footnotetext{
${ }^{8}$ Using a survey experiment, Coibion et al. (2021b) analyze the higher-order expectations of firms in New Zealand. They find that after treated with information about the higher-order expectations of other firms, managers adjust their expectations by much more than after a treatment with information about other firms' first-order expectations.

${ }^{9}$ To compute the VAR based impulse responses, we use the uncertainty measure of Dibiasi and Sarferaz (2021), employing their eight-variable VAR system for Switzerland. Given that their uncertainty measure is based on GDP revisions and the uncertainty shock in our survey experiment on changes in the second moment of turnovers, we re-scale the VAR impulse responses to account for the same size of the shock.
} 

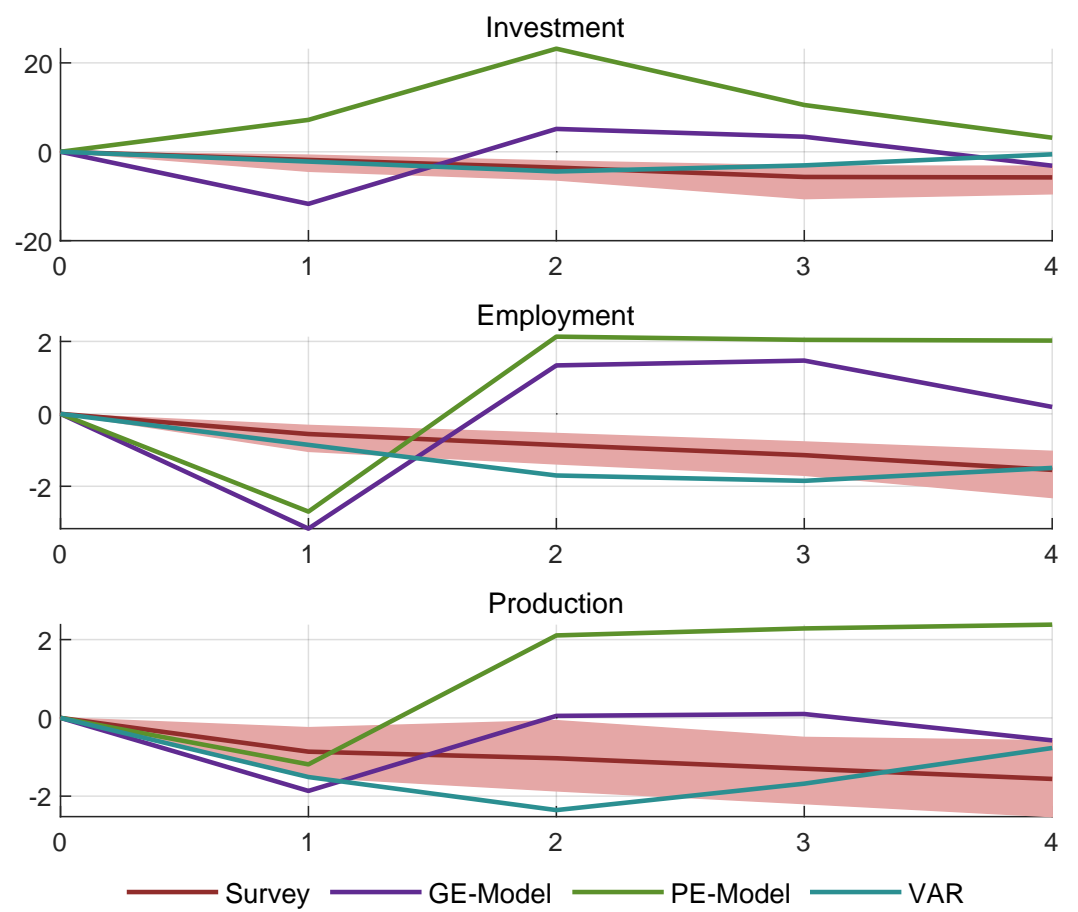

Notes: The red lines are the change in the aggregate of firms' investment, employment and real output plans for the first, second, third and fourth half-yearly horizon after the hypothetical uncertainty shock in percent of the aggregate of the investment, employment or real output plans for the respective horizons in the no shock scenario. The red shaded areas report the $68 \%$ non-parametric bootstrap confidence intervals (Efron and Tibshirani, 1993). The purple lines represent the impulse responses obtained from a model with general equilibrium effects and the green lines are impulse responses computed from a partial equilibrium model. The blue lines show the impulse responses from a VAR.

effect. This pattern is not present in the impulse responses computed from the general equilibrium setup of the model, although there is still a marked drop and rebound effect. The survey responses in contrast are smooth and much more persistent. In that sense, they resemble most the impulse responses computed from a VAR (blue lines). Astonishingly, the VAR impulse responses and the survey responses for investment are quantitatively almost identical up to 1.5 years after the uncertainty shock. For employment and production they are also very similar, especially in the short-run and again 1.5 after the shock. 
The representative aggregate of firm managers' expectation on the shock effects are thus much more in line with general equilibrium models than with models that only take partial equilibrium effects into account. These findings suggest that when extrapolating the effects of a hypothetical uncertainty shock, managers seem to take more into account than just the direct effects of the shock on their firms' figures. The precise indirect effects that managers consider when forming their expectations goes beyond the scope of this paper and is left for future research.

\subsection{Counterfactual Analysis}

What would be the firm managers' expected effect of the uncertainty shock on investment, employment or real output if the capital or labor adjustment cost channels are shut down ceteris paribus? To analyze this question using our survey data, consider the regression model from Equation (4) in its estimated form:

$$
\delta_{i, h}=\boldsymbol{d}^{\prime} \hat{\boldsymbol{\alpha}}+\sum_{j=1}^{J} \hat{\beta}_{j} x_{i, j}+\boldsymbol{z}_{i}^{\prime} \hat{\gamma}+u_{i, h}
$$

Now, suppose that for each firm $i$ the variable $k \in[1, \ldots, J]$ would not have the realization $x_{i, k}$ recorded in the data, but a different realization $x_{i, k}^{c}$. Further, assume that everything else (i.e. the realizations of all other variables, all estimated model parameters and the regression residual value $u_{i, h}$ ) remains unchanged (ceteris paribus assumption). Using the notation from Equation (3), the counterfactual expected level of either investment, employment or real output can then be expressed as

$$
E_{i, t}\left[Y_{i, t+s}^{c} \mid \eta_{t}=1\right]=E_{i, t}\left[Y_{i, t+s} \mid \eta_{t}=0\right] *\left(1+\delta_{i, h}^{c}\right)
$$

where

$$
\delta_{i, h}^{c}=\delta_{i, h}+\hat{\beta}_{k}\left(x_{i, k}^{c}-x_{i, k}\right) .
$$


The counterfactual aggregate responses are calculated analogously to Equation (6):

$$
\delta_{h}^{c}=\frac{\sum_{i}^{n} \omega_{i} E_{i, t}\left[Y_{i, t+h}^{c} \mid \eta_{t}=1\right]-\sum_{i}^{n} \omega_{i} E_{i, t}\left[Y_{i, t+h} \mid \eta_{t}=0\right]}{\sum_{i}^{n} \omega_{i} E_{i, t}\left[Y_{i, t+h} \mid \eta_{t}=0\right]}
$$

Note that the ceteris paribus assumption is counterfactual, since the model parameters would actually change if the variable observations were different. This notwithstanding, the ceteris paribus assumption is the appropriate assumption for the purpose of a counterfactual simulation.

Figure 8 presents counterfactual aggregate responses to the uncertainty shock (red lines) together with bootstrapped $68 \%$ confidence intervals (red shaded areas). The counterfactual aggregate responses are calculated according to Equation (6), where the employed regression specifications are the ones shown in Table 8. For comparison, the figure also includes the actual (i.e. the non-counterfactual) aggregate expected investment responses from Section 4.4 (blue lines).

Underlying the response in the upper-left panel of Figure 8 is the counterfactual that the investment resale value - defined as the price that can be obtained from re-selling all investments directly after their realization, in percent of the total costs for purchasing and installing these investments in the first place - is 100 for each firm in the representative sample $\left(x_{i, k}^{c}=x_{k}^{c}=100\right.$, where variable $k$ denotes the investment resale value). This counterfactual setting shuts down the capital adjustment cost channel for the entire firm sector. The counterfactual responses turn out to be substantially less negative than the actual responses, which confirms the relevance of the adjustment cost channel at the aggregate level. During the first and second half-yearly horizons, expected investment is even higher as compared to expected investment in the no-shock benchmark. Notably, this finding is in line with the general equilibrium results from Section 2. As discussed there, the Oi-Hartman-Abel effect offers a theoretical explanation. While this effect seems 
in the real world to be dominated by the negative effects of the real-options channels, it prevails when the capital adjustment cost channel is counterfactually shut down. A notable difference is that the shutdown of the capital adjustment cost channel in the general equilibrium model yields a persistent investment overshoot in response to the uncertainty shock, whereas the investment overshoot peters out after 1.5 years according to firm managers' expectations in the survey experiment.

Figure 8: Counterfactual Responses
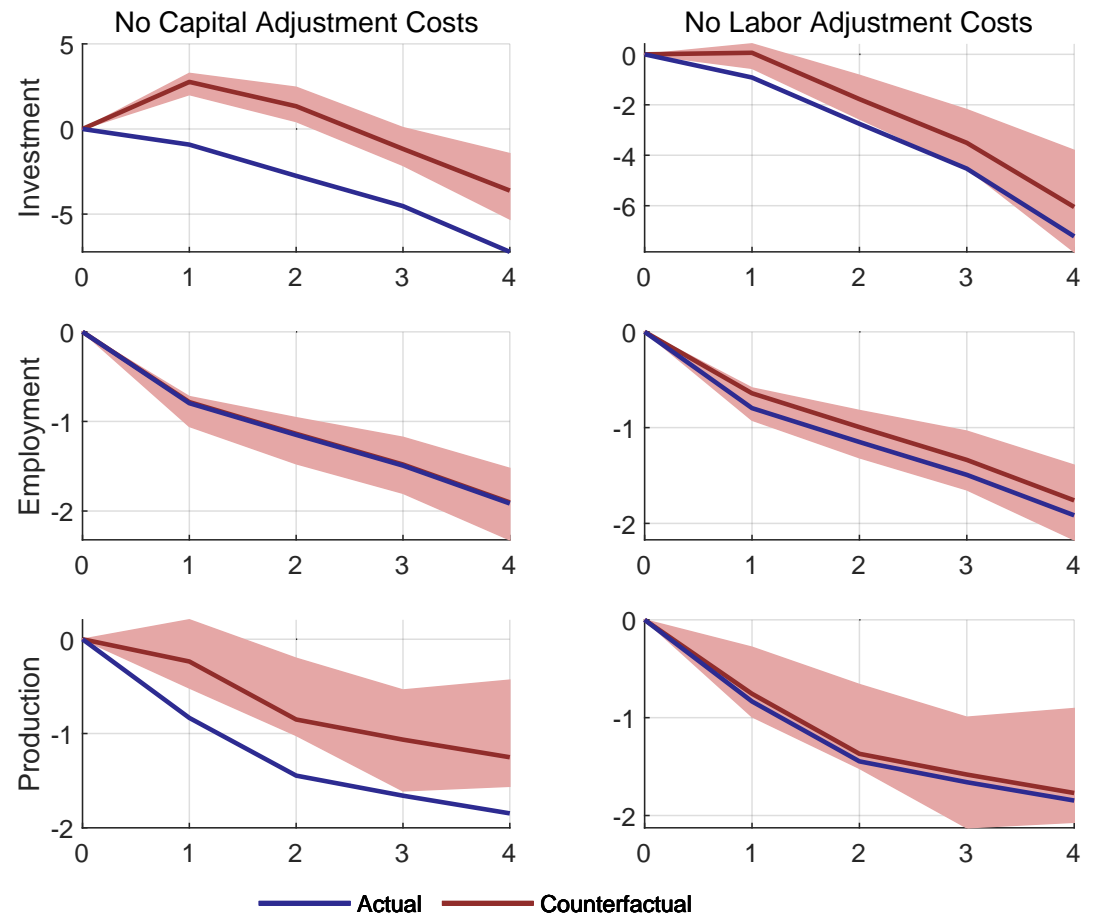

Notes: The red lines depict the counterfactual change in the aggregate of firms' investment, employment and real output plans for the first, second, third and fourth half-yearly horizon after the hypothetical uncertainty shock in percent of the aggregate of the investment, employment and real output plans for the respective horizons in the no shock scenario. The counterfactual responses are calculated according to Equation (6), where the employed regression specifications is the one shown in Table 8. The counterfactual responses in the first (second) column correspond to the case where none of the firms has capital (labor) adjustment costs. The red shaded areas report the $68 \%$ non-parametric bootstrap confidence intervals (Efron and Tibshirani, 1993). The blue lines depict the actual change in the aggregate of firms' investment, employment and real output plans for the four horizons, again in percent of the aggregate of the respective variable for the corresponding horizons in the no shock scenario. 
The upper-right panel of Figure 8 shuts down the labor adjustment cost channel in the economy. The counterfactual here is that labor adjustment costs - measured by the total costs that result, on average, from hiring or dismissing a full-time employee, in percent of the average gross yearly salary of a full-time employee in the firm - are 0 for each firm $\left(x_{i, k}^{c}=x_{k}^{c}=0\right.$, where variable $k$ here denotes the labor adjustment costs $)$. Again, the counterfactual responses turn out to be less negative as compared to the noncounterfactual responses. However, a comparison of the upper-left and the upper-right panel suggests that the capital adjustment cost channel is more relevant than the labor adjustment cost channel. This finding conforms to the general equilibrium analysis from Section 2, according to which a shutdown of the capital adjustment cost channel alters the investment response to an uncertainty shock by more than a shutdown of the labor adjustment cost channel.

The middle panels of Figure 8 iterate the counterfactual analysis for employment. The shutdown of the labor adjustment cost channel mutes the counterfactual employment response a bit. However, neither the capital nor the labor adjustment cost channels are very relevant for how the uncertainty shock affects firms' expected employment at the aggregate level. This contrasts with the general equilibrium analysis from Section 2, where a shutdown of the labor adjustment costs channel almost completely turned off the employment response to the uncertainty shock.

The findings for real output are displayed in the lower panels of Figure 8. As can be seen from the lower-left panel, the shutdown of the capital adjustment cost channel dampens the negative effect of the uncertainty shock scenario on expected real output. Yet, there is no overshooting as for investment. The lower-right panel reveals that the labor adjustment cost channel is only marginally relevant for how the uncertainty shock affects firms' expected real output at the aggregate level. These findings diverge from the general equilibrium results in Section 2. There, a shutdown of the labor adjustment cost 
channel wiped out the output response to the uncertainty shock, whereas a shutdown of the capital adjustment cost channel did not alter the response in the short run.

For robustness, we iterate the analysis based on the regression specifications of Tables 9 and 10 instead of Table 8. Further, we rerun the analysis extending the aforementioned specifications with interaction terms between the horizon-specific intercepts and all capital and labor adjustment variables. This allows the relevance of the channels to vary over the horizons. Appendix D displays the counterfactual responses for the alternative specifications. Across all specifications, the capital cost channel importantly influences how strongly the uncertainty shock affects firms' expected investment and real output at the aggregate level.

\section{Conclusion}

We studied the impact of an uncertainty shock on firms' expected investment, employment and output and the role of capital and labor reversibility therein. For this purpose, we conducted a survey experiment among a representative firm sample of the Swiss economy. The paper made several contributions to the macroeconomic literature on uncertainty. These contributions can be classified in three blocks: provision of measures for capital and labor adjustment costs, evidence on the relevance of capital and labor adjustment costs for the transmission of uncertainty shocks, and a comparison of the survey results with results obtained from DSGE and VAR models. We discuss our contributions in turn and draw conclusions.

The importance of the real-options channel for the transmission of uncertainty shocks on the economy is widely acknowledged in the literature (e.g., Bloom, 2014 and FernándezVillaverde and Guerrón-Quintana, 2020). However, previous research has only indirectly estimated the degree of capital and labor adjustment costs in the economy. There exists 
hardly any empirical evidence on firms' actual adjustment costs. Against this background, our survey levied firms' resale values for different types of capital assets as well as their hiring and firing costs and labor attrition rate. To the best of our knowledge, we are the first ones to provide these direct empirical measures for firm level adjustment costs. ${ }^{10}$ The aggregate net resale value (in terms of original purchasing and installation costs) for intangible assets, tangible assets and real estate in the economy turned out to be $28 \%, 52 \%$ and $75 \%$, respectively. This is less than most indirectly estimated capital resale values used in previous research. Aggregate hiring and firing costs (both in terms of average yearly salary) are $18 \%$ and $9 \%$, respectively, and the aggregate annual labor attrition rate is $10 \%$. Given the extremely wide range of labor adjustment costs used in previous literature, our direct empirical evidence might provide guidance for future research. We further found that capital and labor adjustment costs vary strongly across firms. More interestingly, the form of the firm-level distribution varies considerably across categories. For instance, hiring and firing costs are strongly left-skewed with a high share of firms having adjustment costs close to zero. In contrast, investment resale values are rather equally distributed between 0 and $80 \%$ with few firms above this range. Due to the representativeness of the firm sample, we could compare capital and labor adjustment costs across sector aggregates and size classes. The sectoral variation turned out to be considerable, suggesting differential effects of macroeconomic uncertainty shocks across sectors. For instance, investment resale values are comparatively high in construction and comparatively low in the financial sector. Small firms have substantially lower investment resale values than middle and large firms. Thus, small firms might be less resilient to uncertainty shocks than larger firms. It is noteworthy that the high heterogeneity of capital resale values uncovered by our survey offers an explanation for the broad range of resale value estimates in previous research: depending on what kind of investment or what kind of sector has been included in the analysis, different estimates resulted. A conclusion for further research is that, when modelling uncertainty shocks in heterogeneous

\footnotetext{
${ }^{10}$ We found two exceptions: Del Boca and Rota (1998) collect firing costs among Italian manufacturing firms and Freyens and Oslington (2007) do so for a sample of small Australian firms.
} 
agent models, it might be profitable to introduce heterogeneity in resale values instead of equipping all firms with the same value.

Employing the data collected by the survey, we analyzed the relevance of different types of adjustments costs for the transmission of an uncertainty shock. A firm-level regression analysis yielded that both capital and labor adjustments costs are important factors for explaining the heterogeneity in firms' expected investment responses to the hypothetical shock. Further, it turned out that capital adjustment costs matter especially for firms' real output responses to the shock and labor adjustment costs matter predominantly for employment responses. Dissecting labor adjustment costs into different components, we found that firing costs tend to matter more than hiring costs. Firms' degree of labor attrition turned out to amplify the effect of labor adjustment costs on expected shock responses. To assess the macroeconomic importance of each transmission channel, we reused the firm-level regression coefficients in a counterfactual exercise. Here we analyzed what would be the expected effect of the uncertainty shock at the economy level if a transmission channel is shut down for all firms ceteris paribus. A general finding was that the capital cost channel is more important than the labor cost channel for how strongly the uncertainty shock affects overall expected investment and real output. When shutting down the capital adjustment cost channel, we found evidence for the Oi-Hartman-Abel effect, which is otherwise dominated by negative real-options effects. Notably, these findings, which are elicited from the firm managers' survey responses, are generally in line with the results from a DSGE analysis. Yet, a difference is that the shutdown of the capital adjustment cost channel in the general equilibrium model triggers a persistent investment overshoot in response to an uncertainty shock, while the investment overshoot peters out after 1.5 years according to the managers' expectations.

The use of survey experiments, hypothetical vignettes and randomized control techniques in surveys is spreading quickly in macroeconomic research. Important new insights on the 
expectation building and decision making of economic agents have resulted recently (e.g., Coibion, Gorodnichenko and Ropele, 2020, Christelis et al., 2021, Coibion et al., 2021a, Coibion et al., 2021b, Fuster, Kaplan and Zafar, 2021, and the literature cited in Section 1). Also, researchers have started to explicitly relate findings from the aforementioned approaches to findings from more traditional methods used in macroeconomics (e.g., Andre et al., 2019 and Drechsel et al., 2019). To contribute here, we aggregated the firms' individual investment, employment and real output responses to the hypothetical uncertainty shock to the economy-wide level using statistical techniques for building macro data from firm-level data. The aggregation is feasible due to the representativeness of our firm sample. We then contrasted the aggregate responses to the shock scenario with impulse responses obtained from a partial equilibrium, general equilibrium and a VAR model. The trajectory of the survey based responses appears much closer to impulse responses from a general equilibrium model than to those from a partial equilibrium model. Further, the survey responses resemble most the impulse responses computed from a VAR. Both exhibit a strong, negative and permanent reaction to an uncertainty shock. The aggregate survey responses of firms thus appear to be closer to general equilibrium models and than to a partial equilibrium model. This finding suggests that firms take more than only the direct effects of an uncertainty shock into account when forming their expectations. We leave the exploration of factors that could explain these observations for future research.

\section{References}

Abberger, Klaus, Matthias Bannert, and Andreas Dibiasi. 2014. "Meta-Survey in the Service Sector." KOF Analysen, 8(2): 51-62.

Abel, Andrew B. 1983. "Optimal Investment Under Uncertainty." American Economic Review, 73(1): 228-233. 
Andre, Peter, Carlo Pizzinelli, Christopher Roth, and Johannes Wohlfart. 2019. "Subjective Models of the Macroeconomy: Evidence From Experts and a Representative Sample." CESifo Working Paper No. 7850, CESifo, Munich.

Ariely, Dan, George Loewenstein, and Drazen Prelec. 2003. "Coherent Arbitrariness": Stable Demand Curves Without Stable Preferences." Quarterly Journal of Economics, 118(1): 73-106.

Armantier, Olivier, Scott Nelson, Giorgio Topa, Wilbert Van der Klaauw, and Basit Zafar. 2016. "The Price Is Right: Updating Inflation Expectations in a Randomized Price Information Experiment." Review of Economics and Statistics, 98(3): 503-523.

Armona, Luis, Andreas Fuster, and Basit Zafar. 2018. "Home Price Expectations and Behaviour: Evidence from a Randomized Information Experiment." Review of Economic Studies, 86(4): 1371-1410.

Bachmann, Rüdiger, Steffen Elstner, and Eric R. Sims. 2013. "Uncertainty and Economic Activity: Evidence From Business Survey Data." American Economic Journal: Macroeconomics, 5(2): 217-49.

Basu, Susanto, and Brent Bundick. 2017. "Uncertainty Shocks in a Model of Effective Demand." Econometrica, 85(3): 937-958.

Bernanke, Ben S. 1983. "Irreversibility, Uncertainty, and Cyclical Investment." Quarterly Journal of Economics, 98(1): 85-106.

Binder, Carola, and Alex Rodrigue. 2018. "Household Informedness and LongRun Inflation Expectations: Experimental Evidence." Southern Economic Journal, 85(2): $580-598$.

Bloom, Nicholas. 2009. "The Impact of Uncertainty Shocks." Econometrica, 77(3): 623685. 
Bloom, Nicholas. 2014. "Fluctuations in Uncertainty." Journal of Economic Perspectives, 28(2): 153-76.

Bloom, Nicholas, Max Floetotto, Nir Jaimovich, Itay Saporta-Eksten, and Stephen J. Terry. 2018. "Really Uncertain Business Cycles." Econometrica, 86(3): 1031-1065.

Bloom, Nicholas, Philip Bunn, Scarlet Chen, Paul Mizen, Pawel Smietanka, and Gregory Thwaites. 2019. "The Impact of Brexit on UK Firms." NBER Working Paper No. 26218, National Bureau of Economic Research.

Bloom, Nicholas, Steven J. Davis, Lucia Foster, Brian Lucking, Scott Ohlmacher, and Itay Saporta-Eksten. 2020. "Business-Level Expectations and Uncertainty." NBER Working Paper No. 28259, National Bureau of Economic Research.

Bloom, Nick, Stephen Bond, and John Van Reenen. 2007. "Uncertainty and Investment Dynamics." Review of Economic Studies, 74(2): 391-415.

Caggiano, Giovanni, Efrem Castelnuovo, and Gabriela Nodari. 2020. "Uncertainty and Monetary Policy in Good and Bad Times: A Replication of the VAR Investigation by Bloom (2009)." CAMA Working Paper No. 74/2020, Centre for Applied Macroeconomic Analysis, Australian National University.

Cavallo, Alberto, Guillermo Cruces, and Ricardo Perez-Truglia. 2017. "Inflation Expectations, Learning, and Supermarket Prices: Evidence from Survey Experiments." American Economic Journal: Macroeconomics, 9(3): 1-35.

Christelis, Dimitris, Dimitris Georgarakos, Tullio Jappelli, Luigi Pistaferri, and Maarten Van Rooij. 2019. "Asymmetric Consumption Effects of Transitory Income Shocks." Economic Journal, 129(622): 2322-2341. 
Christelis, Dimitris, Dimitris Georgarakos, Tullio Jappelli, Luigi Pistaferri, and Maarten Van Rooij. 2021. "Heterogeneous Wealth Effects." European Economic Review, In Press.

Cochrane, William G. 1977. Sampling Techniques. Hoboken, NJ: John Wiley \& Sons.

Coibion, Olivier, Dimitris Georgarakos, Yuriy Gorodnichenko, and Maarten Van Rooij. 2019. "How Does Consumption Respond to News About Inflation? Field Evidence From a Randomized Control Trial.” NBER Working Paper No. 26106, National Bureau of Economic Research.

Coibion, Olivier, Dimitris Georgarakos, Yuriy Gorodnichenko, Geoff Kenny, and Michael Weber. 2021a. "The Effect of Macroeconomic Uncertainty on Household Spending." NBER Working Paper No. 28625, National Bureau of Economic Research.

Coibion, Olivier, Yuriy Gorodnichenko, and Michael Weber. 2019. "Monetary Policy Communications and Their Effects on Household Inflation Expectations." NBER Working Paper No. 25482, National Bureau of Economic Research.

Coibion, Olivier, Yuriy Gorodnichenko, and Saten Kumar. 2018. "How Do Firms Form Their Expectations? New Survey Evidence." American Economic Review, 108(9): 2671-2713.

Coibion, Olivier, Yuriy Gorodnichenko, and Tiziano Ropele. 2020. "Inflation Expectations and Firm Decisions: New Causal Evidence." Quarterly Journal of Economics, 135(1): 165-219.

Coibion, Olivier, Yuriy Gorodnichenko, Saten Kumar, and Jane Ryngaert. 2021b. "Do You Know That I Know That You Know...? Higher-Order Beliefs in Survey Data." Quarterly Journal of Economics, Forthcoming. 
Cooper, Russell, John Haltiwanger, and Jonathan L. Willis. 2007. "Search frictions: Matching Aggregate and Establishment Observations." Journal of Monetary Economics, 54: 56-78.

Cooper, Russell W., and John C. Haltiwanger. 2006. "On the Nature of Capital Adjustment Costs." Review of Economic Studies, 73(3): 611-633.

D’Acunto, Francesco, Daniel Hoang, Maritta Paloviita, and Michael Weber. 2019. "Cognitive Abilities and Inflation Expectations." AEA Papers and Proceedings, 109: 562-566.

Dalenius, T., and M. Gurney. 1951. "The Problem of Optimum Stratification. II." Scandinavian Actuarial Journal, 1951(1-2): 133-148.

Del Boca, Alessandra, and Paola Rota. 1998. "How Much Does Hiring and Firing Cost? Survey Evidence From a Sample of Italian Firms." Labour, 12(3): 427-449.

Dibiasi, Andreas, and Samad Sarferaz. 2021. "Measuring Macroeconomic Uncertainty: A Cross-Country Analysis." KOF Working Paper No. 479, KOF Swiss Economic Institute, ETH Zurich.

Dibiasi, Andreas, Klaus Abberger, Michael Siegenthaler, and Jan-Egbert Sturm. 2018. "The Effects of Policy Uncertainty on Investment: Evidence From the Unexpected Acceptance of a Far-Reaching Referendum in Switzerland." European Economic Review, 104: 38-67.

Drechsel, Dirk, Heiner Mikosch, Samad Sarferaz, and Matthias Bannert. 2015. "How are Firms Affected by Exchange Rate Shocks? Evidence from Survey Based Impulse Responses." KOF Working Paper No. 371, KOF Swiss Economic Institute, ETH Zurich. 
Drechsel, Dirk, Heiner Mikosch, Samad Sarferaz, and Matthias Bannert. 2019. "Survey Experimental Impulse Responses." KOF Swiss Economic Institute, ETH Zurich.

Efron, Bradley, and Robert J. Tibshirani. 1993. An Introduction to the Bootstrap. New York: Chapman \& Hall.

European Commission. 2007. "The Joint Harmonised EU Programme of Business and Consumer Surveys. User Guide." Brussels: European Union.

Fernández-Villaverde, Jesús, and Pablo A. Guerrón-Quintana. 2020. "Uncertainty shocks and business cycle research." Review of Economic Dynamics, 37, Supplement 1: S118-S146.

Freyens, Benoit, and Paul Oslington. 2007. "Dismissal Costs and Their Impact on Employment: Evidence From Australian Small and Medium Enterprises." Economic Record, 83(260): 1-15.

Fuster, Andreas, Greg Kaplan, and Basit Zafar. 2021. "What Would You Do With \$500? Spending Responses to Gains, Losses, News and Loans." Review of Economic Studies, In Press.

Fuster, Andreas, Ricardo Perez-Truglia, Mirko Wiederholt, and Basit Zafar. 2020. "Expectations with Endogenous Information Acquisition: An Experimental Investigation." Review of Economics and Statistics, In Press.

Gilchrist, Simon, Jae W. Sim, and Egon Zakrajšek. 2014. "Uncertainty, Financial Frictions, and Investment Dynamics." NBER Working Paper No. 20038, National Bureau of Economic Research.

Guiso, Luigi, and Giuseppe Parigi. 1999. "Investment and Demand Uncertainty." Quarterly Journal of Economics, 114(1): 185-227. 
Gulen, Huseyin, and Mihai Ion. 2015. "Policy Uncertainty and Corporate Investment." Review of Financial Studies, 29(3): 523-564.

Hartman, Richard. 1972. "The Effects of Price and Cost Uncertainty on Investment." Journal of Economic Theory, 5(2): 258-266.

Jappelli, Tullio, and Luigi Pistaferri. 2014. "Fiscal Policy and MPC Heterogeneity." American Economic Journal: Macroeconomics, 6(4): 107-36.

Jappelli, Tullio, and Luigi Pistaferri. 2020. "Reported MPC and Unobserved Heterogeneity." American Economic Journal: Economic Policy, 12(4): 275-97.

Jens, Candace E. 2017. "Political Uncertainty and Investment: Causal Evidence From U.S. Gubernatorial Elections." Journal of Financial Economics, 124(3): 563-579.

Julio, Brandon, and Youngsuk Yook. 2012. "Political Uncertainty and Corporate Investment Cycles." Journal of Finance, 67(1): 45-83.

Jurado, Kyle, Sydney C. Ludvigson, and Serena Ng. 2015. "Measuring Uncertainty." American Economic Review, 105(3): 1177-1216.

Khan, Aubhik, and Julia K. Thomas. 2013. "Credit Shocks and Aggregate Fluctuations in an Economy With Production Heterogeneity." Journal of Political Economy, 121(6): 1055-1107.

Lanteri, Andrea. 2018. "The Market for Used Capital: Endogenous Irreversibility and Reallocation Over the Business Cycle." American Economic Review, 108(9): 2383-2419.

Link, Sebastian, Andreas Peichl, Christopher Roth, and Johannes Wohlfart. 2021. "Information Frictions among Firms and Households." CEBI WORKING PAPER SERIES, Working Paper 07/21.

Liu, Haoyang, and Christopher Palmer. 2021. "Are Stated Expectations Actual Beliefs? New Evidence for the Beliefs Channel of Investment Demand." NBER Working Paper No. 28926, National Bureau of Economic Research. 
Mikosch, Heiner, Christopher Roth, Samad Sarferaz, and Johannes Wohlfart. 2021. "Uncertainty and Information Acquisition: Evidence from Firms and Households." Unpublished manuscript.

Nickell, Stephen J. 1986. "Dynamic Models of Labour Demand." Handbook of Labor Economics, 1: 473-522.

Oi, Walter Y. 1961. "The Desirability of Price Instability Under Perfect Competition." Econometrica, 29(1): 58-64.

Ramey, Valerie A., and Matthew D. Shapiro. 2001. "Displaced Capital: A study of Aerospace Plant Closings." Journal of Political Economy, 109(5): 958-992.

Roth, Christopher, and Johannes Wohlfart. 2020. "How Do Expectations About the Macroeconomy Affect Personal Expectations and Behavior?" Review of Economics and Statistics, 102(4): 731-748. 


\section{Appendix}

This appendix provides supplementary material. Section A expounds how we specify the revenue uncertainty shock in the hypothetical vignette such that the size of the shock is equal for each firm despite differences in the a priori uncertainty. Section B discusses the aggregation procedure used to build representative firm characteristics and representative firm beliefs from the firm-level data. Sections C and D present robustness checks for the regression analyis and the counterfactual analysis on the shock transmission channels. Finally, Section E provides the survey questionnaire.

\section{A Specifying the Uncertainty Shock}

We assume that the turnover of firm $i$ for $i=1, \ldots, N$ at time $t$ for $t=1, \ldots, T$ can be expressed as: ${ }^{11}$

$$
\log \left(A_{i, t}\right)=\log \left(E_{i, t-1}\left[A_{i, t}\right]\right)+\epsilon_{i, t}+\gamma_{i, t}
$$

where $E_{i, t-1}\left[A_{i, t}\right]$ is the turnover that firm $i$ expects for the next period, $\epsilon_{i, t} \sim N\left(0, \sigma_{\epsilon_{i, t}}^{2}\right)$, $E\left[\gamma_{i, t}\right]=0, \operatorname{Cov}\left(\epsilon_{i, t}, \gamma_{i, t}\right)=0$ and

$$
\gamma_{i, t}= \begin{cases}\gamma_{i, H} & \text { with probability } p \\ \gamma_{i, L} & \text { with probability } 1-p\end{cases}
$$

in period $t=s$ and $\gamma_{i, t}=0 \forall t \neq s$.

In our survey experiment, $E_{i, t-1}\left[A_{i, t}\right]$ is self-reported by firm $i$ in period $t-1$. Further, firm $i$ reports in period $t-1$ the $1 \%$ quantile, $\underline{Q}_{i, t}$, and the $99 \%$ quantile, $\bar{Q}_{i, t}$, of its subjective (= perceived) probability distribution $D_{A_{i, t}}$ for the turnover variable $A_{i, t}$ in period $t$. Our aim is to derive expressions for the lower and upper bound of the turnover variable for firm $i$, which allow us to change these bounds by a single scalar value.

\footnotetext{
${ }^{11}$ For $E_{i, t-1}\left[A_{i, t}\right]=A_{i, t-1}$ this is similar to the geometric random walk assumption used in Bloom (2009).
} 
In our survey experiment we set $p=0.5$. Note also that the assumption $E\left[\gamma_{i, t}\right]=0$ and $p=0.5$ imply

$$
\gamma_{i, H}=-\gamma_{i, L}
$$

Define $\eta_{i, t}=\epsilon_{i, t}+\gamma_{i, t}$ with an expected value

$$
\mathrm{E}_{t}\left[\eta_{i, t}\right]=0
$$

and variance ${ }^{12}$

$$
\sigma_{\eta_{i, t}}^{2}=\sigma_{\epsilon_{i, t}}^{2}+\mathrm{E}\left(\gamma_{i, t}^{2}\right)=\sigma_{\epsilon_{i}}^{2}+p \gamma_{i, H}^{2}+(1-p) \gamma_{i, L}^{2}
$$

To set a value for $\gamma$ we want the standard error of $\eta_{i, t}$ to be

$$
\sigma_{\eta_{i, t}}=d \sigma_{\epsilon_{i, t}}
$$

where $\gamma_{i, H}$ and $\gamma_{i, L}$ have to be chosen such that Equation (11) is fulfilled. From Equations (7)-(11) we deduce that

$$
\gamma_{i, H}=\sqrt{\left(d^{2}-1\right)} \frac{\log \left(\bar{Q}_{i, t}\right)-\log \left(E_{i, t-1}\left[A_{i, t}\right]\right)}{2.33}
$$

and

$$
\gamma_{i, L}=-\sqrt{\left(d^{2}-1\right)} \frac{\log \left(\bar{Q}_{i, t}\right)-\log \left(E_{i, t-1}\left[A_{i, t}\right]\right)}{2.33}
$$

Next, define

$$
\log \left(E_{i, t-1}\left[\bar{A}_{i, t}\right]\right)=\log \left(E_{i, t-1}\left[A_{i, t}\right]\right)+\gamma_{i, H}
$$

and

$$
\log \left(E_{i, t-1}\left[\underline{A}_{i, t}\right]\right)=\log \left(E_{i, t-1}\left[A_{i, t}\right]\right)+\gamma_{i, L},
$$

$\overline{{ }^{12} \text { Note that given the above specification of }} \gamma_{i, t}, \sigma_{\eta_{i, t}}^{2}=\sigma_{\epsilon_{i, t}}^{2} \forall s \neq t$ and $\sigma_{\eta_{i, t}}^{2}>\sigma_{\epsilon_{i, t}}^{2}$ for $s=t$. 
which result into the following upper and lower bounds for the turnover of firm $i$ that can be shifted by a scalar $d$

$$
\log \left(E_{i, t-1}\left[\bar{A}_{i, t}\right]\right)=\log \left(E_{i, t-1}\left[A_{i, t}\right]\right)+\sqrt{\left(d^{2}-1\right)} \frac{\log \left(\bar{Q}_{i, t}\right)-\log \left(E_{i, t-1}\left[A_{i, t}\right]\right)}{2.33}
$$

and

$$
\log \left(E_{i, t-1}\left[\underline{A}_{i, t}\right]\right)=\log \left(E_{i, t-1}\left[A_{i, t}\right]\right)-\sqrt{\left(d^{2}-1\right)} \frac{\log \left(\bar{Q}_{i, t}\right)-\log \left(E_{i, t-1}\left[A_{i, t}\right]\right)}{2.33}
$$

In our survey experiment we use $\log \left(E_{i, t-1}\left[A_{i, t}\right]\right)=\log \left(E_{i, t-1}\left[A_{i, t}\right]\right)^{*}=\frac{\log \left(\bar{Q}_{i, t}\right)+\log \left(\underline{Q}_{i, t}\right)}{2}$, ensuring that expressions (14) and (15) are valid even when $\epsilon_{i, t}$ is empirically not normally distributed.

Finally, we set $d=2$ given that we choose to implement an uncertainty shock that implies a doubling of the standard deviation of log turnovers.

\section{B Aggregation}

While studying firm-level data allows us to evaluate the importance of firm characteristics for the understanding of uncertainty shocks, the reactions in an economy on aggregate over all firms might differ significantly from the average firm-level effects. In order for account for this possible difference, we aggregate the firm-level responses using a standard procedure (European Commission, 2007). The procedure ensures that the responses are representative at the economy-wide level and at the sector level. We aggregate firmlevel responses to the national level using a two-step procedure. This procedure differs slightly for level and rate variables. The following section outlines the exact aggregation procedure. 


\section{B.1 Level Variables}

We start from a NACE-2-digit level. The KOF Investment Survey is based on NACE 2008 codes. The population contains 75 2-digit branches (10-33; 35-38; 41-43; 45-47; 49-53; 55-56; 58-66; 68-75; 77-82; 84-96) spanning over 12 letter sectors.

In a first step, for each NACE-2-digit level, we sum up firm-level investment, employment and output. In a second step, we correct for sample decomposition and aggregate to a national level. The correction is based on full time equivalent (FTE) employment and conducted on a NACE-2-digit level. We use the FTE employment on a NACE-2-digit level in the population and employ the FTE employment in our sample to derive sector specific weights. Finally, we compute the aggregate value by summing up the weighted NACE-2-digit level values. Figure 9 depicts the aggregation procedure.

Figure 9: Aggregation Scheme for Level Variables

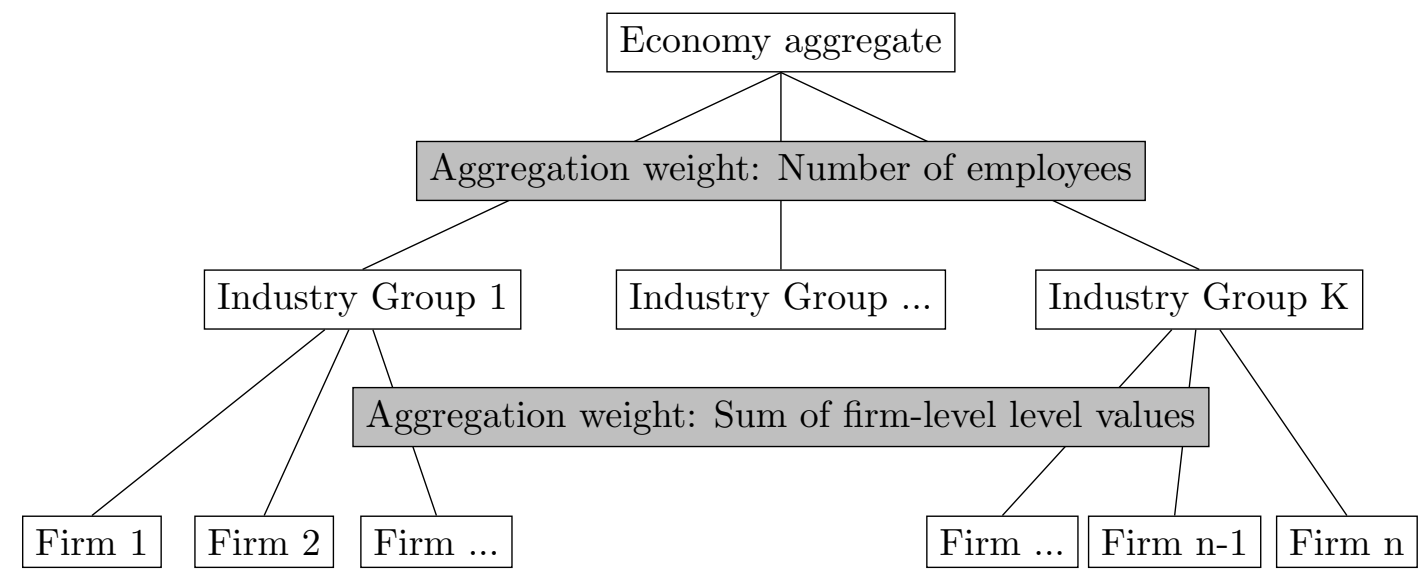


The following equations formally describe the procedure:

$$
\begin{gathered}
\tilde{x}_{k}=\sum_{i=1}^{n} x_{k, i} \\
x_{k}=\tilde{x}_{k} * \frac{u_{k}}{\tilde{u}_{k}} \\
\hat{x}=\sum_{k=1}^{K} x_{k},
\end{gathered}
$$

where

$$
\begin{aligned}
x_{k, i} & :=\text { "level value of firm } i \in\{1, \ldots, n\} \text { in sector } k \in\{1, \ldots, K\} " \\
\tilde{x}_{k} & :=\text { "level value (in sample) for sector } k " \\
x_{k} & :=\text { "level value (population) for sector } k " \\
\hat{x} & :=\text { "aggregate level value for Switzerland" } \\
u_{k} & :=\text { "FTE (population) in sector } k " \\
\tilde{u}_{k} & :=\text { "FTE (in sample) in sector } k "
\end{aligned}
$$

\section{B.2 Rate Variables}

We aggregate our rate variables, i.e. capital resale values measured in percent of the total costs for purchasing and installing the investments in the first place, firing and hiring costs in percent of the average gross yearly salary of a full-time employee in the firm and labor attrition rates in percent of the total number of employees, using again a two-step procedure. However, the aggregation procedure for rate variables differs for the first step slightly from the aggregation of level variables. While for level values, we use the cumulative value of output, employment and investment to obtain NACE-2-digit sector level values, we compute a weighted mean for the rate variables on the NACE-2-digit sector level. We weight firm answers by their firm-level production. In a second step, we aggregate these weighted means using employment weights. Figure 10 depicts the aggregation 
procedure for rate variables.

Figure 10: Aggregation Scheme for Rate Variables

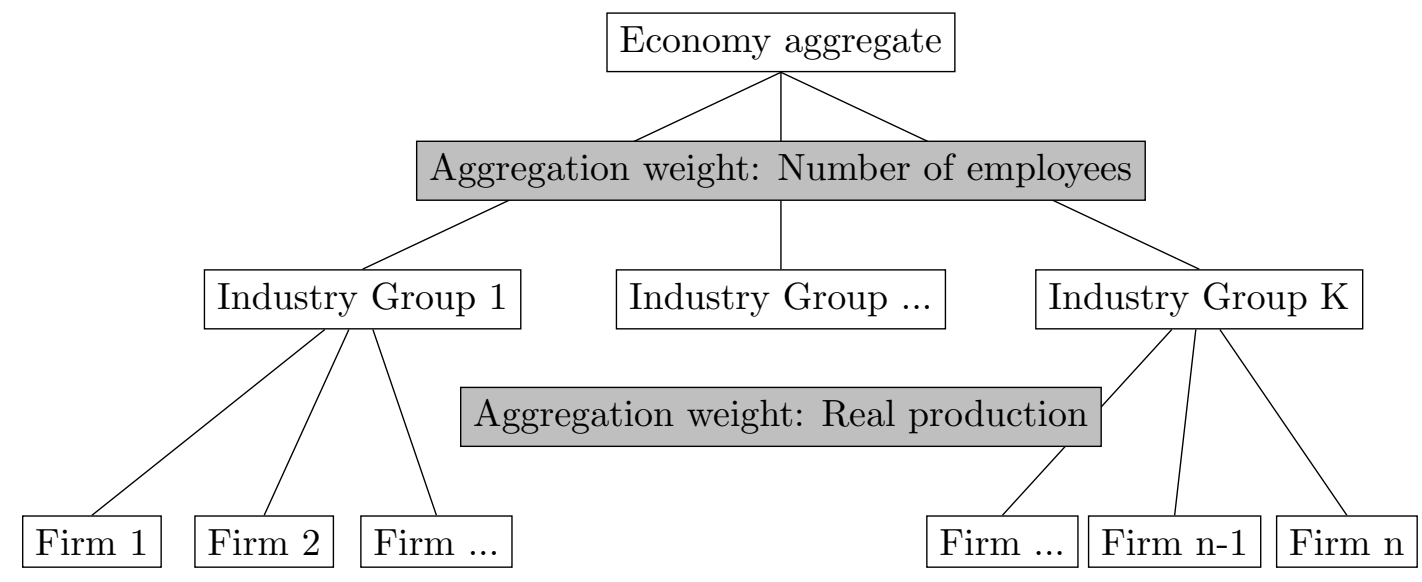

The following equations formally summarize the aggregation procedure for rate variables:

$$
\begin{array}{r}
z_{k}=\sum_{i}^{n} z_{k, i} \frac{y_{k, i}}{\sum_{i}^{n} y_{k, i}} \\
\tilde{w}_{i}=\frac{y_{k, i}, \tilde{u}_{k}}{\sum_{i}^{n} y_{k, i} i u_{k}} \\
\hat{z}=\sum_{i}^{n} z_{k, i} * \tilde{w}_{i},
\end{array}
$$

where

$$
\begin{aligned}
z_{k, i} & :=\text { "rate value of firm } i \text { in sector } k " \\
y_{k, i} & :=\text { "turnover of firm } i \text { in sector } k " \\
\tilde{z}_{k} & :=\text { "average for sector } k " \\
\hat{z} & :=\text { "aggregate value for Switzerland" } \\
u_{k} & :=\text { "FTE (population) in sector } k " \\
\tilde{u}_{k} & :=\text { "FTE (in sample) in sector } k "
\end{aligned}
$$




\section{Robustness for Regression Analysis}

This section shows the robustness checks for the baseline regressions in Table 8. The robustness regressions for Tables 9 and 10 are available on request.

Table 11: Robustness for Investment Regression in Table 8

\begin{tabular}{lcccc}
\hline \hline & $(1)$ & $(2)$ & $(3)$ & $(4)$ \\
& Main & No Trim & Winsorized & Balanced \\
\hline Investment resale value & $0.095^{* * *}$ & $0.090^{* * *}$ & $0.088^{* * *}$ & $0.080^{* *}$ \\
& $(0.030)$ & $(0.034)$ & $(0.031)$ & $(0.032)$ \\
Labor adjustment costs & $-0.077^{* *}$ & $-0.091^{* *}$ & $-0.090^{* *}$ & $-0.135^{* * *}$ \\
& $(0.037)$ & $(0.042)$ & $(0.038)$ & $(0.037)$ \\
Labor attrition rate & -0.032 & 0.010 & 0.015 & 0.005 \\
& $(0.110)$ & $(0.130)$ & $(0.116)$ & $(0.119)$ \\
Initial revenue uncertainty & -0.047 & -0.041 & -0.074 & 0.150 \\
& $(0.136)$ & $(0.160)$ & $(0.143)$ & $(0.150)$ \\
Firm size & 0.000 & 0.000 & 0.000 & $0.000^{*}$ \\
Horizon-specific intercepts & $(0.000)$ & $(0.000)$ & $(0.000)$ & $(0.000)$ \\
Industry-specific dummies & Yes & Yes & Yes & Yes \\
Canton-specific dummies & Yes & Yes & Yes & Yes \\
\hline Observations & 1,096 & 1,128 & 1,128 & 1,092 \\
Adjusted R ${ }^{2}$ & 0.293 & 0.208 & 0.258 & 0.298 \\
\hline
\end{tabular}

Notes: Dependent variable: Firm manager's expected change in investment in response to uncertainty shock relative to no-shock scenario. Column (1): Specification as shown in Table 8 in the main part of the paper. Column (2): Specification with winsorizing the dependent variables at the 1st and 99th percentile instead of trimming. Column (3): Specification without trimming or winsorizing the dependent variables. Column (4): Specification with balancing of the data sample across the three regressions in Table 8. Standard errors in parentheses. ${ }^{*} \mathrm{p}<0.1 ;{ }^{* *} \mathrm{p}<0.05 ;{ }^{* * *} \mathrm{p}<0.01$. 
Table 12: Robustness for Employment Regression in Table 8

\begin{tabular}{lcccc}
\hline \hline & $(1)$ & $(2)$ & $(3)$ & $(4)$ \\
& Main & No Trim & Winsorized & Balanced \\
\hline Investment resale value & 0.0003 & 0.002 & 0.0002 & $0.012^{* * *}$ \\
& $(0.003)$ & $(0.006)$ & $(0.004)$ & $(0.004)$ \\
Labor adjustment costs & $-0.010^{* *}$ & $-0.019^{* *}$ & $-0.012^{* *}$ & -0.006 \\
& $(0.004)$ & $(0.007)$ & $(0.005)$ & $(0.005)$ \\
Labor attrition rate & $0.043^{* * *}$ & $0.042^{*}$ & $0.032^{* *}$ & -0.0002 \\
& $(0.013)$ & $(0.025)$ & $(0.016)$ & $(0.015)$ \\
Initial revenue uncertainty & -0.015 & 0.005 & -0.014 & -0.019 \\
& $(0.016)$ & $(0.030)$ & $(0.019)$ & $(0.019)$ \\
Firm size & 0.000 & 0.000 & 0.000 & 0.000 \\
& $(0.000)$ & $(0.000)$ & $(0.000)$ & $(0.000)$ \\
Horizon-specific intercepts & Yes & Yes & Yes & Yes \\
Industry-specific dummies & Yes & Yes & Yes & Yes \\
Canton-specific dummies & Yes & Yes & Yes & Yes \\
\hline Observations & 1,196 & 1,248 & 1,248 & 1,092 \\
Adjusted R ${ }^{2}$ & 0.412 & 0.212 & 0.339 & 0.390 \\
\hline \hline
\end{tabular}

Notes: Dependent variable: Firm manager's expected change in investment in response to uncertainty shock relative to no-shock scenario. Column (1): Specification as shown in Table 8 in the main part of the paper. Column (2): Specification with winsorizing the dependent variables at the 1st and 99th percentile instead of trimming. Column (3): Specification without trimming or winsorizing the dependent variables. Column (4): Specification with balancing of the data sample across the three regressions in Table 8. Standard errors in parentheses. ${ }^{*} \mathrm{p}<0.1 ;{ }^{* *} \mathrm{p}<0.05 ;{ }^{* * *} \mathrm{p}<0.01$. 
Table 13: Robustness for Output Regression in Table 8

\begin{tabular}{lcccc}
\hline \hline & $(1)$ & $(2)$ & $(3)$ & $(4)$ \\
& Main & No Trim & Winsorized & Balanced \\
\hline Investment resale value & $0.017^{* *}$ & $0.024^{* *}$ & $0.025^{* * *}$ & $0.023^{* * *}$ \\
& $(0.007)$ & $(0.011)$ & $(0.007)$ & $(0.007)$ \\
Labor adjustment costs & -0.006 & -0.015 & -0.012 & 0.003 \\
& $(0.008)$ & $(0.013)$ & $(0.008)$ & $(0.009)$ \\
Labor attrition rate & $0.064^{* *}$ & $0.126^{* * *}$ & $0.091^{* * *}$ & 0.031 \\
& $(0.026)$ & $(0.043)$ & $(0.028)$ & $(0.028)$ \\
Initial revenue uncertainty & -0.041 & -0.006 & -0.023 & $-0.107^{* * *}$ \\
& $(0.031)$ & $(0.052)$ & $(0.034)$ & $(0.035)$ \\
Firm size & -0.000 & -0.000 & -0.000 & -0.000 \\
Horizon-specific intercepts & $(0.000)$ & $(0.000)$ & $(0.000)$ & $(0.000)$ \\
Industry-specific dummies & Yes & Yes & Yes & Yes \\
Canton-specific dummies & Yes & Yes & Yes & Yes \\
\hline Observations & 1,172 & 1,208 & 1,208 & 1,092 \\
Adjusted R ${ }^{2}$ & 0.258 & 0.159 & 0.259 & 0.309 \\
\hline \hline
\end{tabular}

Notes: Dependent variable: Firm manager's expected change in investment in response to uncertainty shock relative to no-shock scenario. Column (1): Specification as shown in Table 8 in the main part of the paper. Column (2): Specification with winsorizing the dependent variables at the 1st and 99th percentile instead of trimming. Column (3): Specification without trimming or winsorizing the dependent variables. Column (4): Specification with balancing of the data sample across the three regressions in Table 8. Standard errors in parentheses. ${ }^{*} \mathrm{p}<0.1 ;{ }^{* *} \mathrm{p}<0.05$; ${ }^{* * *} \mathrm{p}<0.01$. 


\section{Robustness for Counterfactual Analysis}

This section displays the counterfactual responses for alternative regression specifications.

To save space, we show only the counterfactuals with no capital adjustment costs for investment and real output. All other response figures are available on request.

Figure 11: Robustness for Counterfactual Investment Responses

Table 8
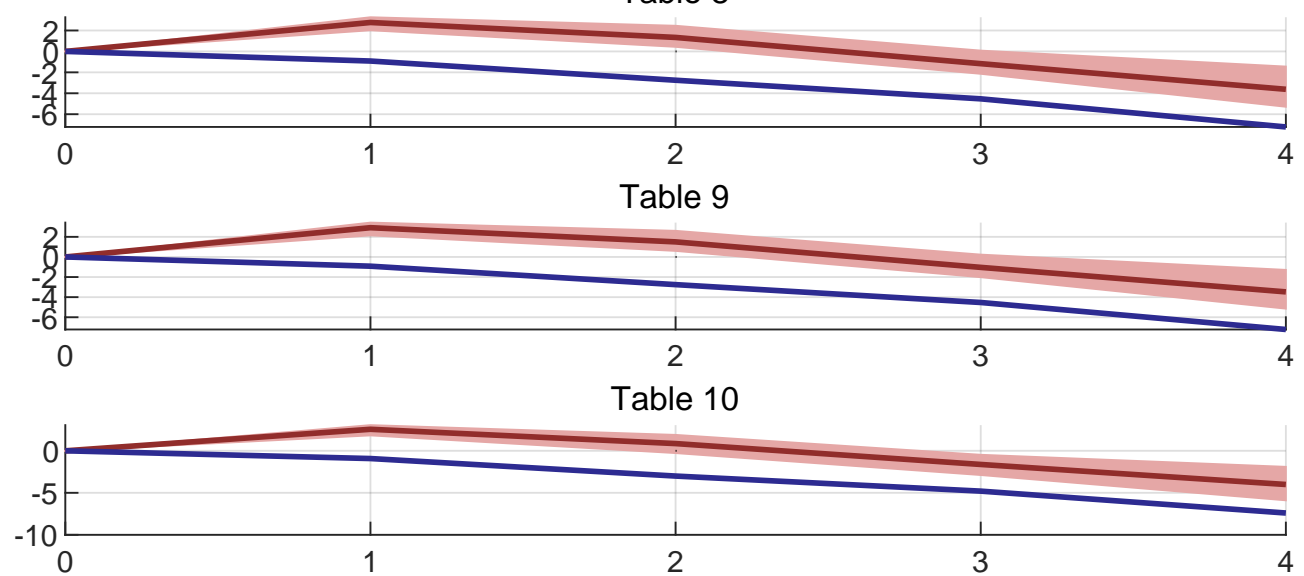

Table 8 with Horizon-Specific Intercept Interactions

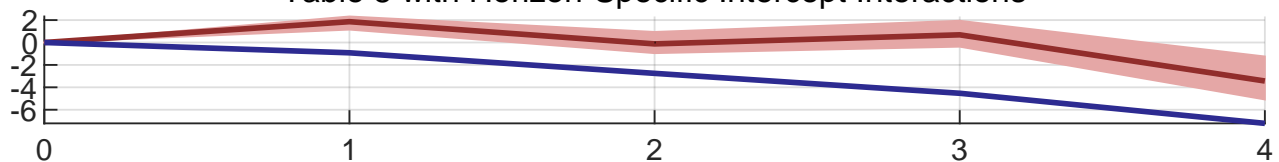

Table 10 with Horizon-Specific Intercept Interactions

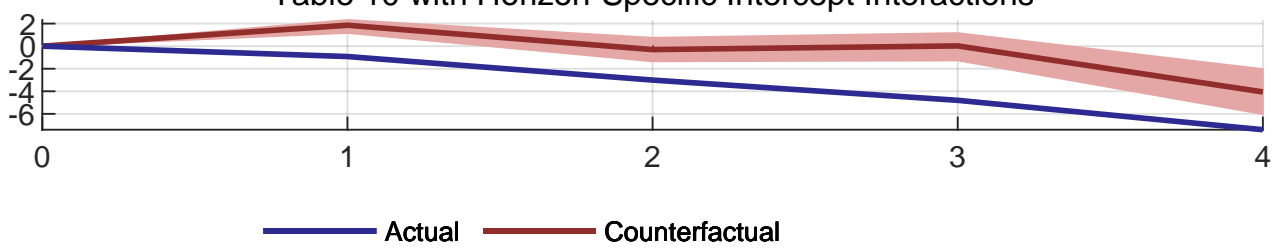

Notes: The red lines depict the counterfactual change in the aggregate of firms' investment plans for the first, second, third and fourth half-yearly horizon after the hypothetical uncertainty shock in percent of the aggregate of the investment plans for the respective horizons in the no shock scenario. The counterfactual responses are calculated according to Equation (6), where the employed regression specification is indicated above each subfigure. The counterfactual in all panel is that that none of the firms has capital adjustment costs. The red shaded areas report the $68 \%$ non-parametric bootstrap confidence intervals (Efron and Tibshirani, 1993). The blue lines depict the actual change in the aggregate of firms' investment plans for the four horizons, again in percent of the aggregate of the investment plans for the respective horizons in the no shock scenario. The first three panels use the specifications summarized in Tables 8, 9 and 10. The fourth and the fifth panel base on the specifications of Table 8 and Table 10 additionally including horizon-specific intercept interactions. 
Figure 12: Robustness for Counterfactual Real Output Responses

Table 8
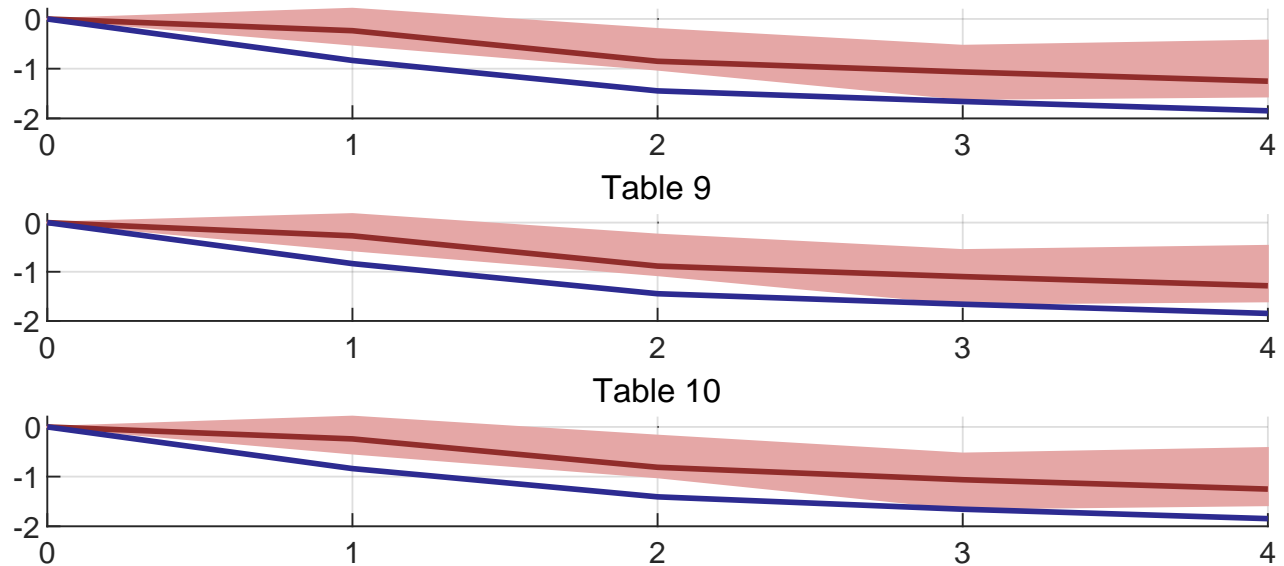

Table 8 with Horizon-Specific Intercept Interactions

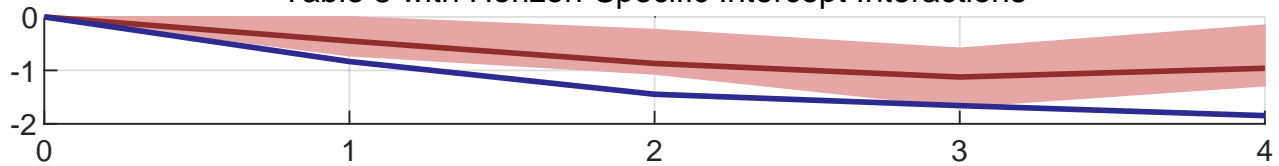

Table 10 with Horizon-Specific Intercept Interactions

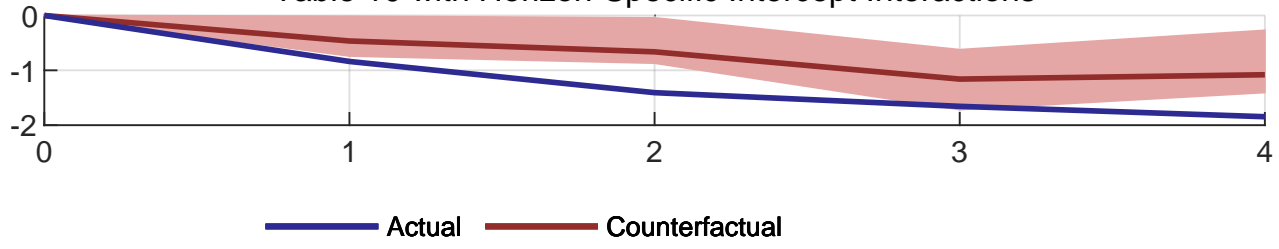

Notes: The red lines depict the counterfactual change in the aggregate of firms' real output plans for the first, second, third and fourth half-yearly horizon after the hypothetical uncertainty shock in percent of the aggregate of the investment plans for the respective horizons in the no shock scenario. The counterfactual responses are calculated according to Equation (6), where the employed regression specification is indicated above each subfigure. The counterfactual in all panels is that none of the firms has capital adjustment costs. The red shaded areas report the $68 \%$ non-parametric bootstrap confidence intervals (Efron and Tibshirani, 1993). The blue lines depict the actual change in the aggregate of firms' investment plans for the four horizons, again in percent of the aggregate of the investment plans for the respective horizons in the no shock scenario. The first three panels use the specifications summarized in Tables 8,9 and 10. The fourth and fifth panel base on the specifications of Table 8 and Table 10 additionally including horizon-specific intercept interactions. 


\section{E Questionnaire}

\section{Special Survey}

Welcome to the special survey on the subject of uncertainty and the economic situation.

Political and economic uncertainty affects entrepreneurial decisions. Companies postpone investments when future demand for their products is particularly uncertain and do not proceed until this uncertainty has disappeared. However, the impact varies from company to company. This survey is designed to investigate the effect of economic uncertainty on the decisions taken in your company (production, investment and attitudes).

Your information will make a valuable contribution to enhancing our understanding of the Swiss economy. The respondents will receive an analysis of the survey results at both the sector and the macroeconomic level.

\section{Basic information}

1. Your company's turnover (excluding VAT) at the Swiss site (including goods/services delivered abroad (approximate figure) in 2015:

2015

$\mathrm{CHF}$

2. Your company's operating expenses (including personnel expenses, cost of materials, other operating expenses, depreciation) in Switzerland in 2015:

2015

$\mathrm{CHF}$

3. Your personnel expenses in 2015:

2015

$\mathrm{CHF}$

4. Please state the expected range of your annual net turnover at the Swiss site in 2018.

Top of range:

2018

$\mathrm{CHF}$

Bottom of range:

2018

$\mathrm{CHF}$

\section{Explanation:}

Please enter the top figure (total annual turnover in 2018) in the upper field (1\% probability that the actual turnover will exceed this figure).

Please enter the bottom figure (total annual turnover in 2018) in the lower field (1\% probability that the actual turnover will be below this figure). 
5. Please also state which annual turnover figure within the range is most likely.

Expected value:

2018

In the following, we will ask some general questions regarding your company.

6. What is the total expected value of the services provided / goods delivered in the coming periods? Please put a price-indexed value on the goods/services at current selling prices in order to calculate the total value.

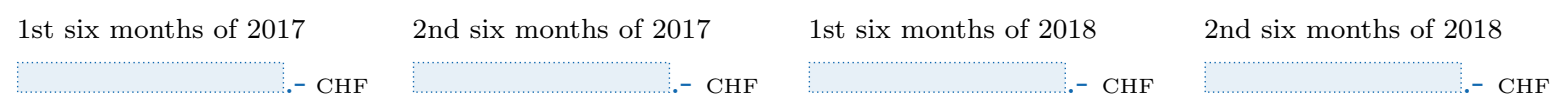

7. Your expected gross investments in plant and machinery in Switzerland in the coming periods:

Please specify investments at acquisition/production cost.

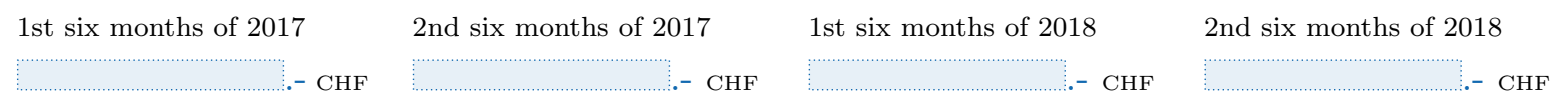

8. Please assume that, due to operational reasons, you will have to sell the investments made in 2017 and 2018 directly after their realization.

In your opinion, what will their resale value (net residual value) be?

(as a percentage of the total investments stated above)

$\begin{array}{l:l:}\text { Real estate } & \% \\ \text { Intangible assets } & \% \\ \text { (including IT) } & \% \\ \text { Mobile tangible assets } & \\ \text { (excluding IT) } & \% \\ \text { Not relevant } & \end{array}$

In the context of this question, we are investigating a hypothetical value that plays a central role in the economy. In specific, we are interested in the decline of an investment's price directly after its acquisition. We are therefore asking you about the price at which you could resell an investment directly after its purchase. If you could sell an investment at acquisition price, the resale value would be $100 \%$. If you could not sell the investment at all, its resale value would be $0 \%$. We are aware that this is a hypothetical value and that an exact figure is difficult to provide. Nevertheless, we hope that you can give us a rough estimate.

9. What is your projected number of staff (including temporary staff, trainees and family members helping out) in the coming periods?

(in full-time equivalents) 
10. What is the projected number of temporary staff in the coming periods?

(in full-time equivalents)

1st six months of 2017

2nd six months of 2017

1st six months of 2018

2nd six months of 2018
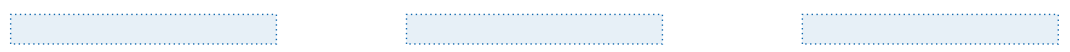

.

11. What was the estimated cost of recruiting a new full-time employee (e.g. advertising, recruitment agency, selection process, training, on-the-job training, etc.) in 2015? A rough estimate is sufficient.

(as a percentage of the average annual salary (including additional benefits) of a new full-time employee)

2015

$\%$

12. In your experience, which average costs are associated with a statutory dismissal by the employer (e.g. severance pay, lawyer's or court costs, release from work, reduced working hours, etc.)?

(as a percentage of the average annual salary of a new full-time employee)

\section{$\%$}

13. What is the annual fluctuation rate in your company (including voluntary departures and retirement)?

(average figure of the last few years)

\section{$\%$}

14. How do you rate your corporate culture: Is your company generally prepared to take entrepreneurial risks or does it try and avoid such risks where possible?

Please tick a figure on the scale below, where 0 means: 'not at all prepared to take risks' and 10 means: 'very willing to take risks'. Tick a value in-between for a graduated response.

$\begin{array}{cccccccccc}0 & 1 & 2 & 3 & 4 & 5 & 6 & 7 & 8 & 9 \\ \square & \square & \square & \square & \square & \square & \square & \square & \square & \square\end{array}$

15. In response to one of the questions above, you provided the following estimate of your long-term future net turnover (net annual turnover in 2018):

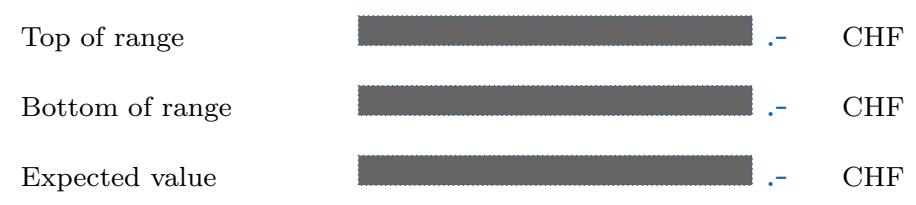

Please imagine the following scenario: 
At the beginning of April 2017, the Federal Council announces that it will put an initiative to the vote in July 2017 that will have a substantial impact on your future turnover. If the initiative is voted in, the impact on your demand will be positive, if it is rejected the effect will be negative.

Recent polls show that around $50 \%$ of Swiss voters are currently in favour of the initiative. The percentage of voters who reject the initiative is also $50 \%$.

The initiative will affect your long-term expected turnover (net annual turnover in 2018) as follows:

if the initiative is accepted

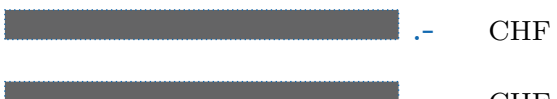

if the initiative is rejected

CHF

16. How would you adapt your current plans in the above scenario?

What is the total value of the services provided / goods delivered in the coming periods? Please put a price-indexed value on the goods/services at current selling prices in order to calculate the total value.

1st six months of 2017

. $\mathrm{CHF}$ 2nd six months of 2017

1st six months of 2018

$-\mathrm{CHF}$ 2nd six months of 2018 $-\mathrm{CHF}$

17. How would you adapt your current plans in the above scenario?

In the above scenario, your company's expected gross investments in plant and machinery in Switzerland in the coming periods is:

1st six months of 2017

. 2nd six months of 2017

- $\mathrm{CHF}$ 1st six months of 2018

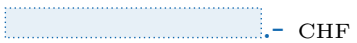

2nd six months of 2018

- $\mathrm{CHF}$

18. How would you adapt your current plans in the above scenario?

Your projected number of staff (including temporary staff) in the coming periods:

1st six months of 2017

2nd six months of 2017

$\ldots$ 1st six months of 2018

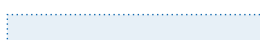

2nd six months of 2018

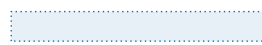

19. How would you adapt your current plans in the above scenario?

Your projected number of temporary staff in the coming periods: 
Thank you very much for taking part in this survey! Your answers will make a valuable contribution to enhancing our understanding of the Swiss economy. We will forward the survey results to you as soon as they are available. If you have any questions, please do not hesitate to contact us at xxx@kof.ethz.ch or on 04463 2XX XX. 